\title{
The Effect of Sun Elevation on the Twilight Stages in Malaysia
}

\author{
Yasser Abdel-Fattah Abdel-Hadi, Amir Hussein Hassan \\ Solar and Space Research Department, National Research Institute of Astronomy and Geophysics (NRIAG), Helwan, Cairo, \\ Egypt \\ Email: yasser_hadi@yahoo.com
}

How to cite this paper: Abdel-Hadi, Y.A.-F. and Hassan, A.H. (2022) The Effect of Sun Elevation on the Twilight Stages in Malaysia. International Journal of Astronomy and Astrophysics, 12, 7-29. https://doi.org/10.4236/ijaa.2022.121002

Received: November 7, 2021

Accepted: February 8, 2022

Published: February 11, 2022

Copyright (c) 2022 by author(s) and Scientific Research Publishing Inc. This work is licensed under the Creative Commons Attribution International License (CC BY 4.0).

http://creativecommons.org/licenses/by/4.0/

(c) (i) Open Access

\begin{abstract}
This study is concerned with determining the altitude of the sun under the horizon to the beginning and the end of the true and pseudo dawn and dusk. In 2007 and 2008, the Sky Quality Meter (SQM) was used in four regions in Malaysia to measure the brightness at night, pseudo dawn, true dawn, true dusk and pseudo dusk. The measurements were taken when the device was directed to the position of sunrise and sunset at the horizontal angle of the sunrise or sunset and at five degrees above the horizon during the entire monitoring period. The altitude of the sun for the true dusk was found to be $-14.38^{\circ} \pm 0.91^{\circ}$ and for the beginning of the pseudo dusk was found to be $-14.86^{\circ} \pm 0.91^{\circ}$ and the end of the pseudo dusk is $-17.8^{\circ} \pm 0.7^{\circ}$, while for the beginning of the true dawn it was found to be $-14.19^{\circ} \pm 0.52^{\circ}$ (for high confidence $-14.71^{\circ}$ ) and for the pseudo dawn was found to be $-18.62^{\circ} \pm 0.82^{\circ}$. The light magnitude of the full night after the pseudo dusk was found to be $20.77 \pm 0.93 \mathrm{mag} . / \mathrm{arcsec}^{2}$, while it was found to be $22.17 \pm 0.1 \mathrm{mag} . / \operatorname{arcsec}^{2}$ before the pseudo dawn.
\end{abstract}

\section{Keywords}

Twilight, Light Magnitude, Altitude of the Sun, Beginning of the True Dusk, Beginning of the True Dawn, Pseudo Dusk, Pseudo Dawn, Full Night, SQM

\section{Introduction}

The study of the twilight of various types is extremely important for large segments of the society, especially astronomers, to study the planets during the twilight for the length of the twilight in the summer months in the upper latitudes [1]. When the sun reaches a depression of $10^{\circ}-15^{\circ}$ below the horizon, the intrinsic glow of the upper atmospheric layers begins to appear together with star- 
light, and the illumination conditions gradually approach those of night. The transition to night is usually complete when the sun is depressed $17^{\circ}-19^{\circ}$ below the horizon [2].

Humans can distinguish about 7 to 10 million different colors just name them and build an instrument that identifies them [3]. Miethe and Lehmann reported observations of the dawn and dusk in Aswan of Egypt $\left(24^{\circ} 6^{\prime} \mathrm{N}, 30^{\circ} 45^{\prime} \mathrm{E}\right.$ and $160 \mathrm{~m}$ Elev.) in the winter of 1908 and by a camera made especially for this purpose. The conclusion of their results was that the first light appeared from the east at $a=$ $-17.35^{\circ}$ and the first appearance of color difference (true dawn) was at $a=$ $-14.25^{\circ}$, while the beginning of the true dusk was at a drop of the sun under the horizon by at $a=-14.9^{\circ}$ [4]. Nawar [5] studied the spectral photometry of the zodiacal light near the tropic of cancer at Daraw and Abu-Simble in Egypt by a photometer in the BVR regions. Photoelectric observational model of the zodiacal light brightness and polarizations in the blue, yellow and red colors has been suggested during quiet solar activity. The ratios of the zodiacal light brightness at minimum solar activity to that at maximum solar activity are 1.3 and 1.7 for the observations carried out at low and high altitudes above sea level respectively. The maximum brightness of zodiacal light occurs during the new moon, which is 1.29 times the brightness at lunar age 10 days. The brightness of the zodiacal light, for the observations carried out at high altitudes above sea level, is larger than that deduced at low altitudes by mean factors are 1.5 and 2 for small and large elongations respectively [5]. David [6] and Reach [7] studied the origin of the zodiacal cloud and carbonaceous micrometeorites (the zodiacal cloud is a thick circumsolar disk of small debris particles produced by asteroid collisions and comets). The particles produced by Jupiter family comets (JFCs) are scattered by Jupiter before they are able to decouple from the planet and drift down to $1 \mathrm{AU}$. Therefore, the inclination distribution of JFC particles is broader than that of their source comets and leads to good fits to the broad latitudinal distribution of fluxes observed by Infrared Astronomical Satellite (IRAS). About $85 \%$ to $95 \%$ of the observed mid-infrared emission is produced by particles from JFCs and $<10 \%$ by dust from long-period comets. Patat et al. [8] studied the UBVRI twilight brightness at dome C [9] and found that the night sky brightness level is reached around zenith angle of the sun between $105^{\circ}$ and $106^{\circ}$. The results of this work show the rate of the total spectrum got converted from the positive to negative signs at solar altitude of $a=-14.8^{\circ}$. The Rayleigh-scattered sun flux clearly contributes in the region bluewards of 5000 $\AA$ down to $a=-15^{\circ}$, after which the pseudo-continuum of the night sky emission takes over.

Several published works for the true dawn according to the photoelectric measurements in the desert background at different sites in Egypt showed that it appears in the sun altitude range between $-14^{\circ}$ and $-15^{\circ}$. The naked eye observations for the desert background in several regions in Egypt, Libya and Saudi Arabia showed that the true dawn happens at $a=-14.7^{\circ}$ in the desert areas, 
while it happens for the agriculture and coastal areas (in Egypt and Libya) at $a=$ $-13.5^{\circ}$. The total number of observations taken in these researches by both photometer and naked eye exceeds 1300 observations. The published work of the evening twilight (end of twilight or end of the pseudo dusk) showed that it ranges between $-18^{\circ}$ and $-19^{\circ}$ according to the photoelectric measurements in the desert area at different sites in Egypt. Table 1 summarizes the published work of observing twilight in different locations and methods using the naked eye (N.E.), camera and photoelectric (P.E.) for the true dawn and the end of pseudo dusk (end of twilight).

Table 2 represents the twilight brightness conditions at the major level of the civil, nautical and astronomical twilights [14]. There is a great expansion in recent times in the use of the SQM in the twilight and light pollution observations around the world because it is sufficient and easy to carry, especially in desert and remote areas [23] [24] [25].

The objective of this study is to determine the limits of the light magnitude against the sun vertical depression below the horizon for: pseudo dawn, true dawn, true dusk and pseudo dusk at different locations in Malaysia.

Table 1. Summarization of the published work of observing twilight using naked eye (N.E.), camera and photoelectric (P.E.) for the true dawn and end of the pseudo dusk, where the sun vertical depression $D_{o} \equiv-a$.

\begin{tabular}{|c|c|c|c|c|c|c|c|c|}
\hline Location & Lat. N & Long. E & Elev. (m) & Location & Method & $\begin{array}{c}D_{o}, \text { True } \\
\text { Dawn }\end{array}$ & $\begin{array}{c}D_{o}, \text { End of } \\
\text { Pseudo Dusk }\end{array}$ & Authors \\
\hline Riyadh (Saudi Arabia) & $25^{\circ} 46^{\prime}$ & $74^{\circ} 12.16^{\prime}$ & 540 & Desert & N.E \& Camera & $14.6^{\circ} \pm 0.3^{\circ}$ & & {$[10]$} \\
\hline Bahria (Egypt) & $28^{\circ} 42.9^{\prime}$ & $29^{\circ} 59.82^{\prime}$ & 150 & Desert & P.E. & $15.5^{\circ}$ & $19.5^{\circ}$ & {$[11]$} \\
\hline Bahria oasis, (Egypt) & $28^{\circ} 42.9^{\prime}$ & $29^{\circ} 59.82^{\prime}$ & 150 & Desert & P.E. & $14^{\circ} \pm 0.5^{\circ}$ & $19.5^{\circ} \pm 0.5^{\circ}$ & {$[12]$} \\
\hline Kottamia (Egypt) & $29^{\circ} 55.9^{\prime}$ & $31^{\circ} 49.5^{\prime}$ & 470 & Desert & P.E. & $14.5^{\circ}$ & $19^{\circ}$ & {$[13]$} \\
\hline Tanjung Aru (Malaysia) & $5^{\circ} 57^{\prime}$ & $116^{\circ} 02^{\prime}$ & 4 & Desert & SQM & & $18^{\circ} \pm 0.16^{\circ}$ & {$[14]$} \\
\hline Matrouh (Egypt) & $31^{\circ} 0.2^{\prime}$ & $27^{\circ} 51^{\prime}$ & 75 & Sea-Desert & P.E. & $15^{\circ} \pm 1^{\circ}$ & $19^{\circ} \pm 1^{\circ}$ & {$[15]$} \\
\hline Bahria (Egypt) & $28^{\circ} 42.9^{\prime}$ & $29^{\circ} 59.82^{\prime}$ & 150 & Desert & P.E. & $\leq 15^{\circ}$ & $\leq 18^{\circ}$ & {$[16]$} \\
\hline Bahria (Egypt) & $28^{\circ} 42.9^{\prime}$ & $29^{\circ} 59.82^{\prime}$ & 150 & Desert & N.E. & $14.7^{\circ}$ & & {$[17]$} \\
\hline Matrouh (Egypt) & $31^{\circ} 0.2^{\prime}$ & $27^{\circ} 51^{\prime}$ & 75 & Sea-Desert & N.E. & $14.5^{\circ}$ & & {$[17]$} \\
\hline Kottamia (Egypt) & $29^{\circ} 55.9^{\prime}$ & $31^{\circ} 49.5^{\prime}$ & 470 & Desert & N.E. & $14.66^{\circ} \pm 0.2^{\circ}$ & & {$[17]$} \\
\hline Aswan (Egypt) & $23^{\circ} 48.22^{\prime}$ & $32^{\circ} 29.5^{\prime}$ & 210 & Desert & N.E. & $13.96^{\circ}$ & & {$[17]$} \\
\hline Tubruq (Libya) & $32^{\circ} 4.7^{\prime}$ & $23^{\circ} 59^{\prime}$ & 40 & Desert & N.E. & $14.7^{\circ}$ & & {$[18]$} \\
\hline Sinai (Egypt) & $31^{\circ} 04^{\prime}$ & $32^{\circ} 52^{\prime}$ & 10 & Desert & N.E. & $14.61^{\circ}$ & & [19] \\
\hline Assiut (Egypt) & $27^{\circ} 10^{\prime}$ & $31^{\circ} 10^{\prime}$ & 52 & Agricultural & N.E. & $13.48^{\circ}$ & & {$[19]$} \\
\hline Hail (Saudi Arabia) & $25^{\circ} 46^{\prime}$ & $47^{\circ} 12^{\prime}$ & 540 & Desert & N. E. & $14.66^{\circ}$ & & {$[20]$} \\
\hline Wadi El Natron (Egypt) & $30^{\circ} 30^{\prime}$ & $30^{\circ} 09^{\prime}$ & 30 & Desert & N.E. & $14.57^{\circ}$ & & {$[21]$} \\
\hline Depok (Indonesia) & $6^{\circ} 27^{\prime} \mathrm{S}$ & $106^{\circ} 48^{\prime} \mathrm{E}$ & $50-140$ & Sea-Desert & SQM & $14^{\circ} \pm 0.6^{\circ}$ & & {$[22]$} \\
\hline
\end{tabular}


Table 2. Twilight brightness conditions [14].

\begin{tabular}{ccccc}
\hline $\begin{array}{c}\text { Dusk Stages of } \\
\text { twilight }\end{array}$ & $\begin{array}{c}\text { Altitude } \\
\text { degree }\end{array}$ & Illuminance lux & $\begin{array}{c}\text { Luminance } \\
\mathrm{cd} / \mathrm{m}^{2}\end{array}$ & $\begin{array}{c}\text { Lower Limit of Sky } \\
\text { Brightness (mag./arcsec }{ }^{2} \text { ) }\end{array}$ \\
\hline Civil & $-6^{\circ}$ & 3.4 & 1.08 & $12.42^{\mathrm{m}}$ \\
Nautical & $-12^{\circ}$ & $8.31 \times 10^{-3}$ & $2.64 \times 10^{-3}$ & $19.03^{\mathrm{m}}$ \\
Astronomical & $-18^{\circ}$ & $6.52 \times 10^{-4}$ & $2.08 \times 10^{-4}$ & $21.79^{\mathrm{m}}$ \\
\hline
\end{tabular}

\section{Methodology and Data Acquisition}

The basic concepts on which this research is based are:

1) Each time interval in the twilight has its own optical characteristics.

2) The idea of this research depends on the determination of the beginning and the end of the pseudo dusk and the pseudo dawn.

3) The full night after the pseudo dusk and before the pseudo dawn gives a state of optical stability (minimum change in the light magnitude).

The measured data were recorded by Sky Quality Meter (SQM-LE) by Nafhatun [26] and also by personal contacts. The Sky Quality Meter was adapted for its complete performance in this research. It is not a spot meter because it accepts light from a wide cone-roughly 80 degrees diameter. The measurement of twilight sky brightness is performed in various sites covering east and west coast of Malaysia from May 2007 to April 2008 intermittently. For averting unwanted light, a special hood was used in front of the detectors. All measurements of the light intensity in dusk and dawn are at about 5 degrees above the horizon, at azimuth sunrise and sunset directions. The data were recorded in two minutes interval. Table 3 represents the coordinate of site observations at latitude $(\varphi)$, longitude $(\lambda)$, elevation (Elev.) and the date of observation for evening twilight (dusk) and morning twilight (dawn)of the places in Malaysia, which have been used in this research. Table 4 represents the selected dates and cities of observation sites or the evening twilight (dusk) and morning twilight (dawn) under the study.

\section{Results and Discussion}

The symbol of $\left(m_{n}\right)$ stands for the magnitude through the time intervals of the light. The sequence of light intervals magnitudes for the evening twilight is: true dusk $\left(m_{1}\right)$, pseudo dusk $\left(m_{2}\right)$, full night after pseudo dusk $\left(m_{3}\right)$ respectively. Similarly, for the morning twilight they are: full night before pseudo dawn $\left(m_{4}\right)$, pseudo dawn $\left(m_{5}\right)$ and true dawn $\left(m_{6}\right)$ respectively.

\subsection{For the Evening Twilight}

Figures 1-4 show the relation between the light magnitude (mag./ $\left(\mathrm{arsec}^{2}\right)$ and the altitude of the sun (a) for different time intervals of true dusk $\left(m_{1}\right)$, pseudo dusk $\left(m_{2}\right)$ and full night $\left(m_{3}\right)$ at different days and different places in Malaysia. These figures generally show that there are three phases of light from the sunset to the full night according to the sun vertical depression below the horizon. The 
Table 3. Coordinates and altitudes of observation sites.

\begin{tabular}{cccc}
\hline Site & Latitude $(\varphi)$ & Longitude $(\lambda)$ & Elev. \\
\hline Kuala Lumpur, Federal Territory & $3^{\circ} 9^{\prime} \mathrm{N}$ & $101^{\circ} 41^{\prime} \mathrm{E}$ & $60 \mathrm{~m}$ \\
Teluk Kemang, Negeri Sembilan & $2^{\circ} 28^{\prime} \mathrm{N}$ & $101^{\circ} 52^{\prime} \mathrm{E}$ & $27 \mathrm{~m}$ \\
Kuala Lipis, Pahang & $4^{\circ} 11^{\prime} \mathrm{N}$ & $102^{\circ} 3^{\prime} \mathrm{E}$ & $75 \mathrm{~m}$ \\
Port Klang, Selangor & $3^{\circ} \mathrm{N}$ & $101^{\circ} 24^{\prime} \mathrm{E}$ & $46 \mathrm{~m}$ \\
Merang, Terengganu & $5^{\circ} 31^{\prime} \mathrm{N}$ & $102^{\circ} 57^{\prime} \mathrm{E}$ & $42 \mathrm{~m}$ \\
\hline
\end{tabular}

Table 4. Dates and cities of observation sites for dusk and dawn.

\begin{tabular}{cc}
\hline Dusk & Dawn \\
\hline Date, City & Date, City \\
\hline 15-06-2007, TelukKemang & $8-5-2007$, Merang \\
13-8-2007, TelukKemang & $10-11-2007$, Kuala Lipis \\
4-9-2007, Kuala Lumpur & $29-12-2007$, Kuala Lipis \\
27-10-2007, Kuala Lumpur & $11-1-2008$, Kuala Lipis \\
5-11-2007, Kuala Lipis & $9-2-2008$, Kuala Lipis \\
29-12-2007, Kuala Lipis & $22-3-2008$, Kuala Lipis \\
12-1-2008, Kuala Lipis & $23-3-2008$, Kuala Lipis \\
9-2-2008, Kuala Lipis & $7-4-2008$, Port Klang \\
$22-3-2008$, Kuala Lipis & \\
$23-3-2008$, Kuala Lipis & \\
$5-4-2008$, Port Klang & \\
$6-4-2008$, Port Klang &
\end{tabular}

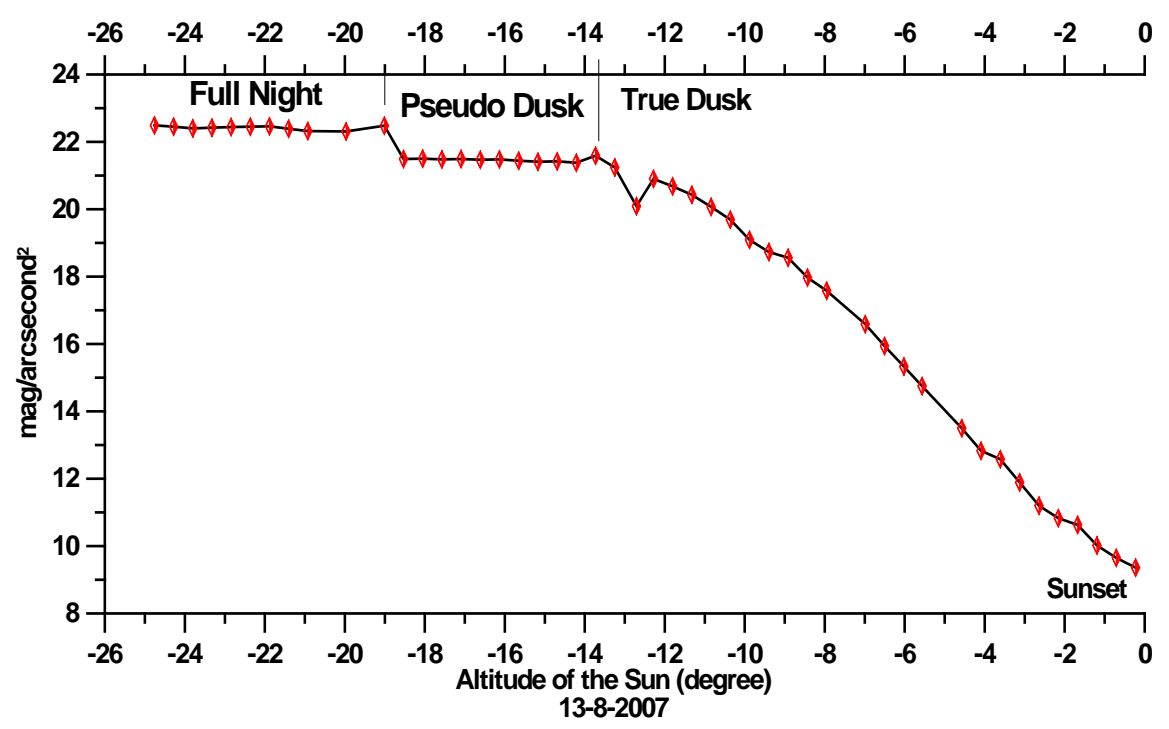

Figure 1. The relation between the light magnitude (mag./ $\operatorname{arcsec}^{2}$ ) and the altitude (a) of the sun for different time interval of the evening twilight for the true dusk, the pseudo dusk (zodiacal light) and the full night on $13^{\text {th }}$ August 2007 in Teluk Kemang. 


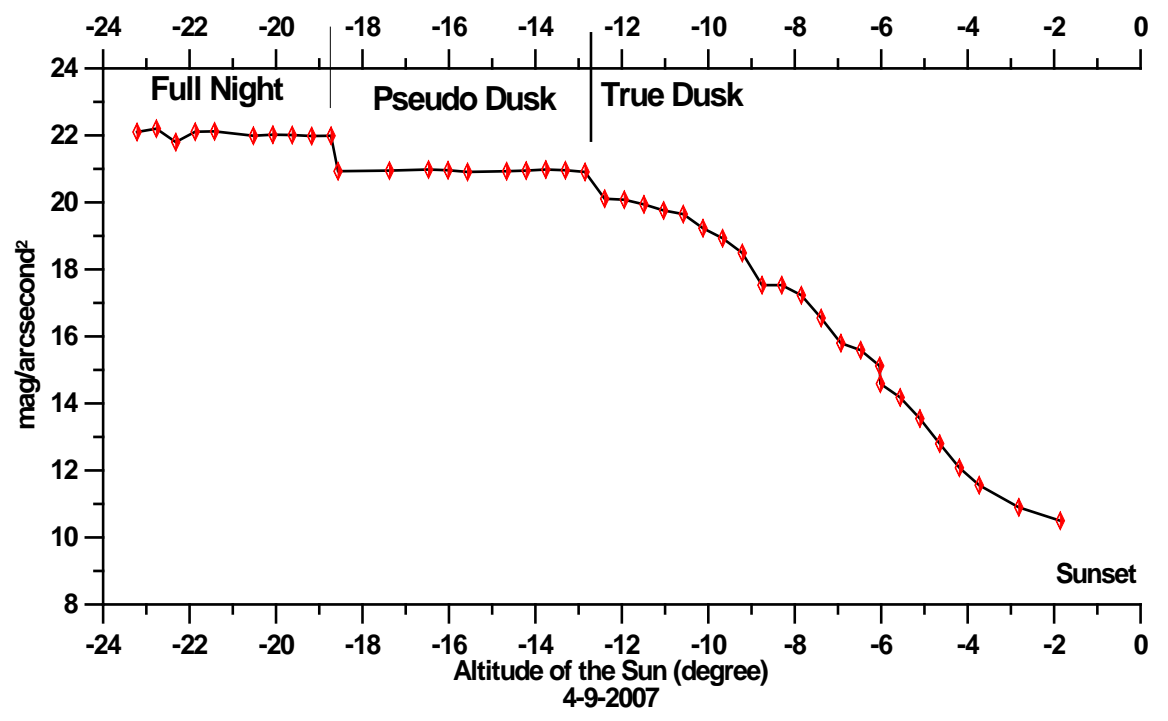

Figure 2. The relation between the light magnitude (mag./arcsec ${ }^{2}$ ) and the altitude (a) of the sun for different time interval of the evening twilight for the true dusk, the pseudo dusk (zodiacal light) and the full night on $4^{\text {th }}$ September 2007 in Kuala Lumpur.

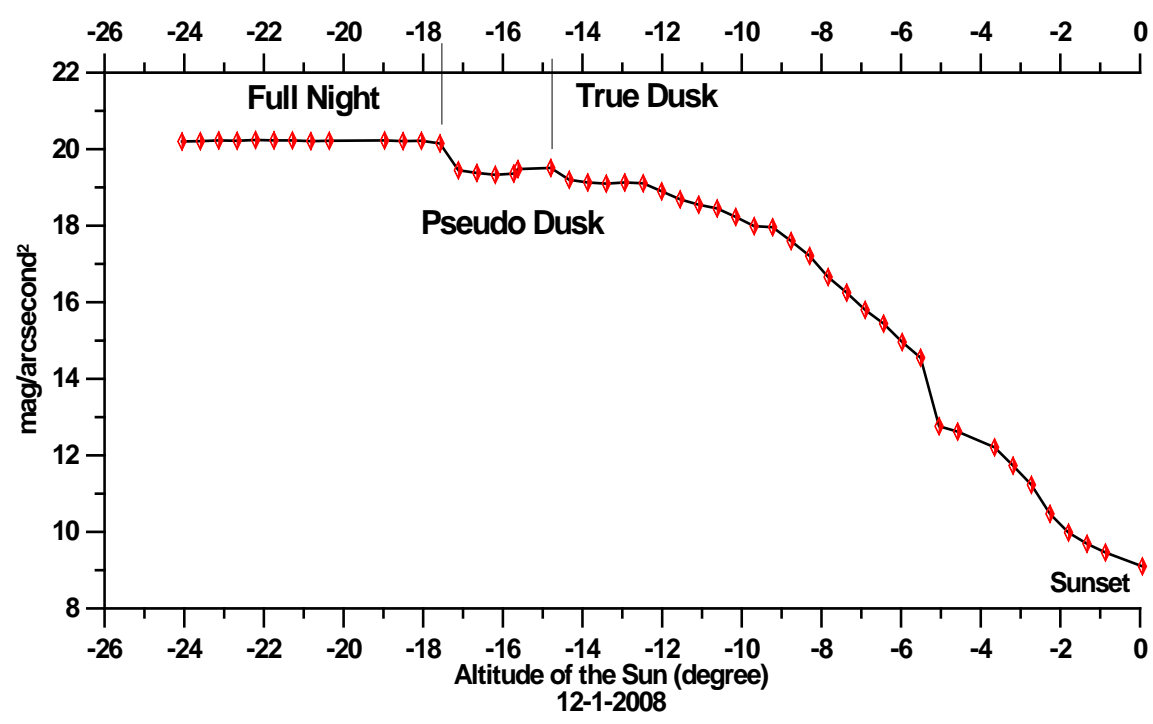

Figure 3. The relation between the light magnitude (mag./ $\operatorname{arcsec}^{2}$ ) and the altitude (a) of the sun for different time interval of the evening twilight for the true dusk, the pseudo dusk (zodiacal light) and the full night on $12^{\text {th }}$ January 2008 in Kuala Lipis.

main feature characterizing the first time interval is the rapid change in the light until a sun vertical depression of $14.5^{\circ}$. Then, a very slight change in light characterizes the second time interval until a sun vertical depression of approximately $18.5^{\circ}$ which represents a pseudo dusk (zodiacal light). Finally, the full night characterizes the third time interval which is the interval of approximately no change in the light. The duration and the light magnitude vary from day to day of the pseudo dusk depending on the weather characteristics of the night. Under the light of Figure 5, which represents selected 12 clear observing nights, it is clear that the sun vertical depression from $14.5^{\circ}$ to $18.5^{\circ}$ is the state of the 


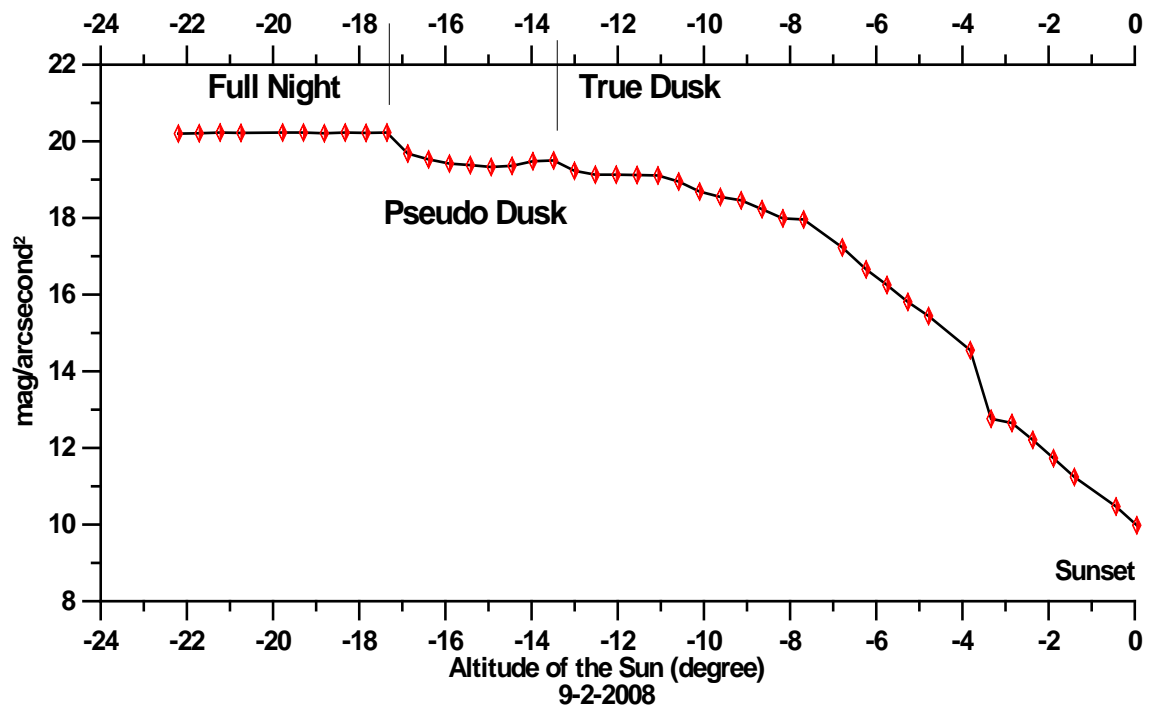

Figure 4. The relation between the light magnitude (mag./arcsec ${ }^{2}$ ) and the altitude (a) of the sun for different time interval of the evening twilight for the true dusk, the pseudo dusk (zodiacal light) and the full night on $9^{\text {th }}$ February 2008 in Kuala Lipis.

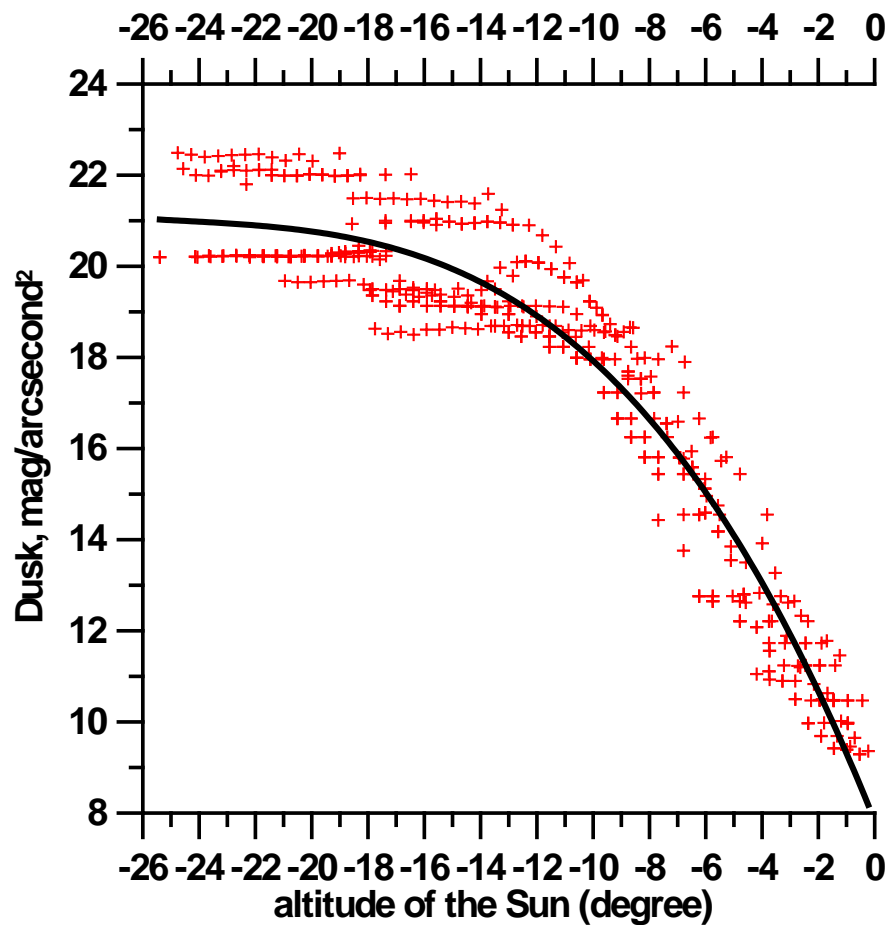

Figure 5. The relation between the light magnitude (mag./ $\operatorname{arcsec}^{2}$ ) and altitude (a) of the sun for the evening twilight for the true dusk, the pseudo dusk (zodiacal light) and the full night for all days of observation.

pseudo dusk $\left(m_{2}\right)$, where the complete hierarchical shape of the pseudo dusk is not frequently observed. It continues vertically for a while and ends as a transverse band that lasts for about $4^{\circ}$ of sun altitude. Then, after a sun altitude of $-18.5^{\circ}$, there is a state of stability of light that represents the full night $\left(m_{3}\right)$. There is a range of about $2^{\mathrm{m}}\left(20-22 \mathrm{mag} . / \mathrm{arcsec}^{2}\right)$ in the light magnitudes be- 
tween some nights due to the difference in the atmosphere luminance between winter and summer, which is in turn due to the difference in temperature and humidity between each of them. These observations are distinguished by the total clarity between three light intervals.

Table 5, Table 6 and Figure 5 represent the light magnitudes and the sun altitude for the true dusk ( $m_{1}$ and $a_{1}$ ), the beginning of the pseudo dusk $\left(m_{12}\right.$ and $\left.a_{12}\right)$, the end of the pseudo dusk and the beginning of full night $\left(m_{23}\right.$ and $\left.a_{23}\right)$. The disappearance of the true dusk is at a magnitude of $19.63^{\mathrm{m}} \pm 0.92$ and a sun vertical depression of $-14.38^{\circ} \pm 0.91^{\circ}$, while the beginning of the pseudo dusk is at a light magnitude of $19.78^{\mathrm{m}} \pm 0.87$ and a sun vertical depression of $-14.86^{\circ} \pm$ $0.91^{\circ}$. Also the end of the pseudo dusk is at a light magnitude of $20.06^{\mathrm{m}} \pm 0.927$ and a sun vertical depression of $-17.8^{\circ} \pm 0.7^{\circ}$. The difference of the depression of the pseudo dusk is $\Delta a_{2}=2.96^{\circ} \pm 1.16^{\circ}$ (the range of the pseudo dusk is mean $+1 S D=4.3^{\circ}$ ). This means that the astronomical twilight altitude $18^{\circ}$ is easily around the end of the pseudo dusk which is the beginning of the full night. This result agrees with Rozenberg (1966) stating verbally "the transition to night is usually complete when the sun is depressed between $17^{\circ}$ and $19^{\circ}$ below the horizon". Accordingly, the full night begins after a sun vertical depression of $18^{\circ}$ which is characterized by no change in the light magnitude. The interval of altitude depression for the full night values under the study is $\Delta a_{3} \approx 8.4^{\circ}$ (mean $+2 \mathrm{SD}$ ) showing the total time interval of the observed full night. The light magnitude values of the pseudo dusk is limited between the values of $m_{1}\left(19.63^{\mathrm{m}} \pm\right.$ $0.92)$ and $m_{2}\left(19.77^{\mathrm{m}} \pm 0.93\right)$.

Table 5. The beginning and end of the true and the pseudo dusk in terms of the light magnitude $m_{i j}$ (mag./arcsec $\left.{ }^{2}\right)$ and the altitude of the sun below the horizon $\left(a_{i j}\right)$.

\begin{tabular}{ccccccc}
\hline Dusk & \multicolumn{2}{c}{ Begin of True dusk } & \multicolumn{2}{c}{ Begin of pseudo dusk } & \multicolumn{2}{c}{ End of Pseudo dusk } \\
\hline Date & $m_{1}$ & $a_{1}$ & $m_{12}$ & $a_{12}$ & $m_{23}$ & $a_{23}$ \\
\hline $15-06-2007$ & 20.95 & -14.213 & 20.9 & -14.665 & 21 & -17.38 \\
$13-8-2007$ & 21.42 & -14.69 & 21.4 & -15.172 & 21.49 & -18.53 \\
$4-9-2007$ & 20.91 & -12.85 & 20.96 & -13.31 & 21.99 & -18.72 \\
$27-10-2007$ & 19.09 & -15.34 & 19.7 & -15.821 & 19.73 & -17.26 \\
$11-1-2008$ & 19.2 & -14.42 & 19.51 & -14.866 & 19.58 & -18.11 \\
$29-12-2007$ & 18.7 & -13.6 & 18.62 & -14.10 & 19.60 & -18.2 \\
$12-1-2008$ & 19.2 & -14.33 & 19.5 & -14.797 & 19.45 & -17.116 \\
$9-2-2008$ & 19.23 & -13.003 & 19.5 & -13.487 & 19.68 & -16.87 \\
$22-3-2008$ & 19.13 & -14.938 & 19.2 & -15.422 & 20.45 & -18.32 \\
$23-3-2008$ & 19.13 & -14.938 & 19.2 & -15.422 & 19.48 & -17.93 \\
$5-4-2008$ & 18.95 & -13.97 & 19.1 & -14.454 & 19.36 & -17.84 \\
$6-4-2008$ & 19.13 & -14.938 & 19.2 & -15.422 & 19.13 & -16.87 \\
Mean & 19.63 & -14.38 & 19.78 & -14.86 & 20.06 & -17.80 \\
SD & 0.92 & 0.91 & 0.87 & 0.91 & 0.927 & 0.697 \\
\hline
\end{tabular}


Table 6. The measured values of the pseudo dusk and the full night light magnitudes $m_{i}$ (mag./arcsec $\left.{ }^{2}\right)$ of the sun altitude intervals $\left(\Delta a_{i}\right)$.

\begin{tabular}{ccccc}
\hline Dusk & \multicolumn{2}{c}{ Pseudo dusk limit } & \multicolumn{2}{c}{ Full night after the pseudo dusk } \\
\hline Date & $\Delta a_{2}$ & $m_{2}$ & $\Delta a_{3}$ & $m_{3}$ \\
\hline $15-06-2007$ & 2.71 & $20.99 \pm 0.036$ & 3.14 & $21.997 \pm 0.0138$ \\
$13-8-2007$ & 3.36 & $21.47 \pm 0.03$ & 5.75 & $22.42 \pm 0.06$ \\
$4-9-2007$ & 5.36 & $20.95 \pm 0.023$ & 4.49 & $22.03 \pm 0.109$ \\
$27-10-2007$ & 1.44 & $19.7 \pm 0.0216$ & 6.25 & $21.467 \pm 0.067$ \\
$29-12-2007$ & 4.58 & $18.62 \pm 0.0627$ & 2.8 & $19.66 \pm 0.03$ \\
$11-1-2008$ & 3.71 & $19.46 \pm 0.0886$ & 5.55 & $20.237 \pm 0.026$ \\
$12-1-2008$ & 2.32 & $19.42 \pm 0.072$ & 6.48 & $20.215 \pm 0.022$ \\
$9-2-2008$ & 3.39 & $19.46 \pm 0.113$ & 4.84 & $20.22 \pm 0.011$ \\
$22-3-2008$ & 2.50 & $19.31 \pm 0.173$ & 3.87 & $20.23 \pm 0.022$ \\
$23-3-2008$ & 2.50 & $19.33 \pm 0.17$ & 3.87 & $20.24 \pm 0.031$ \\
$5-4-2008$ & 3.39 & $19.26 \pm 0.16$ & 7.46 & $20.25 \pm 0.045$ \\
$6-4-2008$ & 1.45 & $19.26 \pm 0.177$ & 4.35 & $20.27 \pm 0.054$ \\
Mean & 3.06 & 19.77 & 5.15 & 20.77 \\
SD & 1.16 & 0.87 & 1.37 & 0.93 \\
Variance & & 0.758 & & 0.865 \\
\hline
\end{tabular}

In the same way, the light magnitude values for the end of the pseudo dusk $m_{23}$ $\left(20.06^{\mathrm{m}} \pm 0.93\right)$ is a boundary point between the end of the pseudo dusk and the beginning of the full night $m_{3}\left(20.77^{\mathrm{m}} \pm 0.93\right)$ representing a depression at which the darkness increases as much as $0.71^{\mathrm{m}}$.

Also from Table 6, it is noticed that, the values of variance are relatively close to each other and ranging from $0.76^{\mathrm{m}}$ to $0.86^{\mathrm{m}}$ in both the pseudo dusk $\left(m_{2}\right)$ and the full night $\left(m_{3}\right)$, which indicates the state of stability. On the other hand, in the case of the pseudo dusk, the light detected is just the zodiacal light, which glows the atmosphere creating a hierarchical shape that disappears afterwards when the earth moves around the sun. The difference in magnitude between the zodiacal light (pseudo dusk) and the full darkness is about one magnitude $\left(20.77^{\mathrm{m}} \pm 0.87\right.$ to $\left.19.77^{\mathrm{m}} \pm 0.93\right)$. The standard deviation (SD) of the observation days of the pseudo dusk $\left(m_{2}\right)$ ranges from $0.023^{\mathrm{m}}$ to $0.177^{\mathrm{m}}$, which expresses the greatest stability for each single night for that light region, while the values of the full night $\left(m_{3}\right)$ range from $0.011^{\mathrm{m}}$ to $0.109^{\mathrm{m}}$.

\subsection{For the Morning Twilight}

Figures 6-9 show the relation between the light magnitude (mag./arcsec ${ }^{2}$ ) and the altitude of the sun (a) below the horizon for different stages of the morning twilight from the full night to the sunrise on different days and at different places in Malaysia. Generally, these figures show the existence of three light regions 


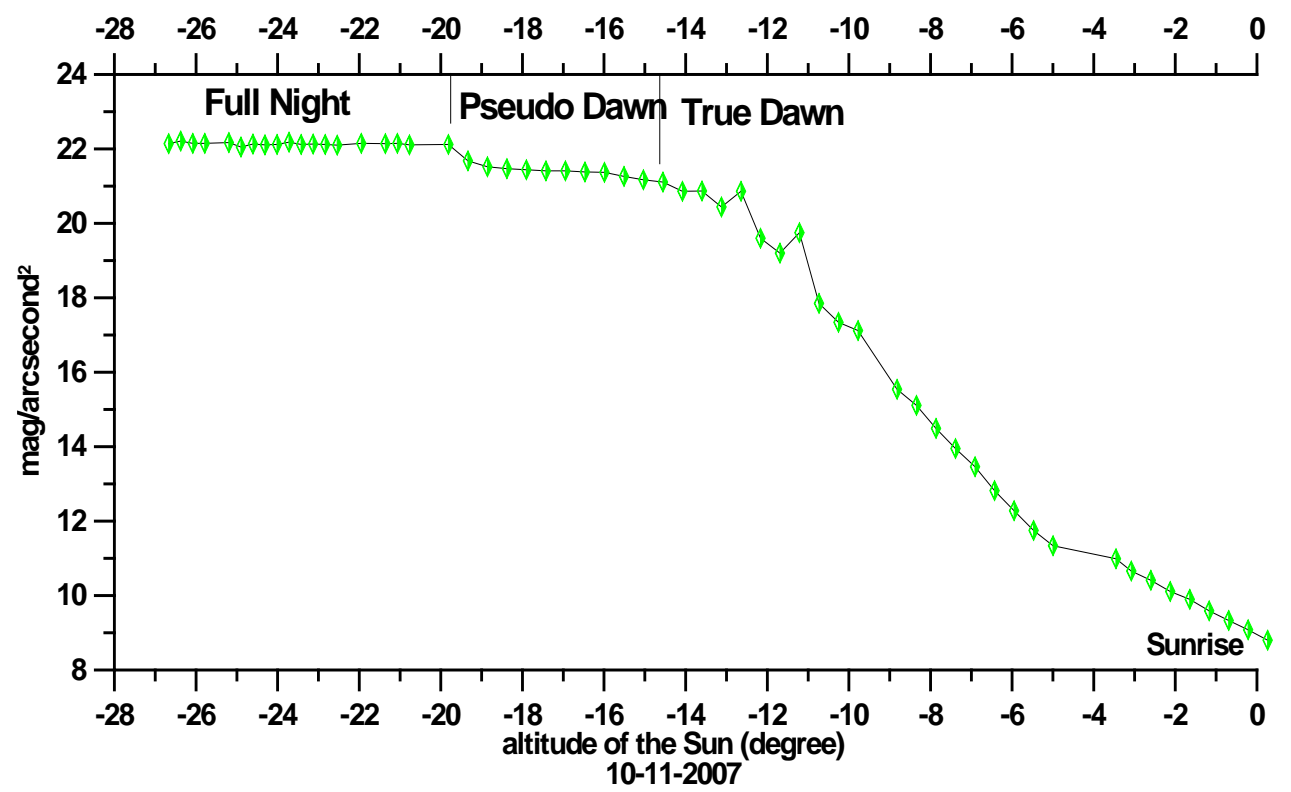

Figure 6. The relation between the light magnitude (mag./arcsec ${ }^{2}$ ) and altitude (a) of the sun for different time interval of the morning twilight for the full night, the pseudo-dawn (zodiacal light) and the true dawn on $10^{\text {th }}$ November 2007 in Kuala Lipis.

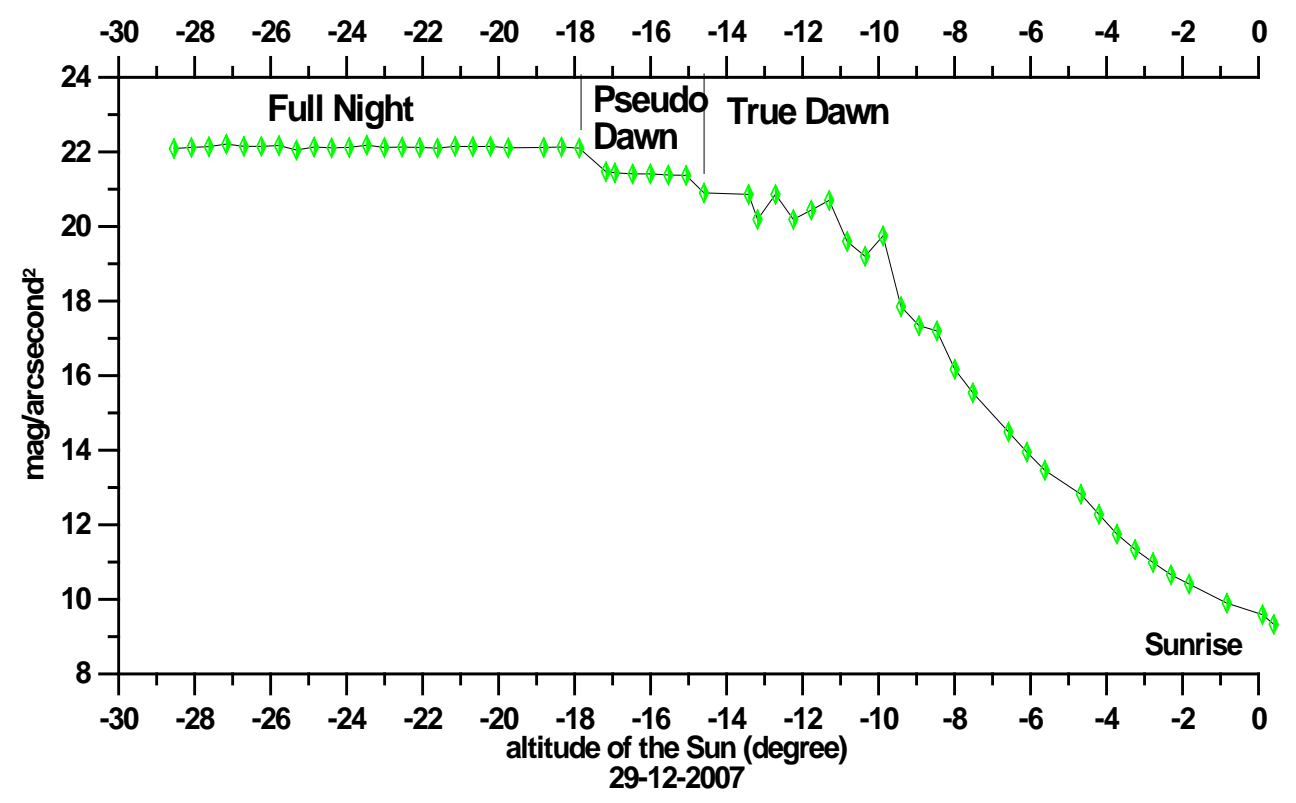

Figure 7. The relation between the light magnitude (mag./arcsec ${ }^{2}$ ) and altitude (a) of the sun for different time interval of the morning twilight for the full night, the pseudo-dawn (zodiacal light) and the true dawn on $29^{\text {th }}$ December 2007 in Kuala Lipis.

which are characterized in terms of light intensity from the full night around $18^{\circ}$ of sun vertical depression until the sunrise.

Figure 9 shows clearly that the zodiacal light (pseudo-dawn) has a hierarchical shape which appears after the full night on April 7 and that the optical intensity changes during the zodiacal light and darkness and does not return back to the same value. This pattern does not appear clearly every day. The brightness 


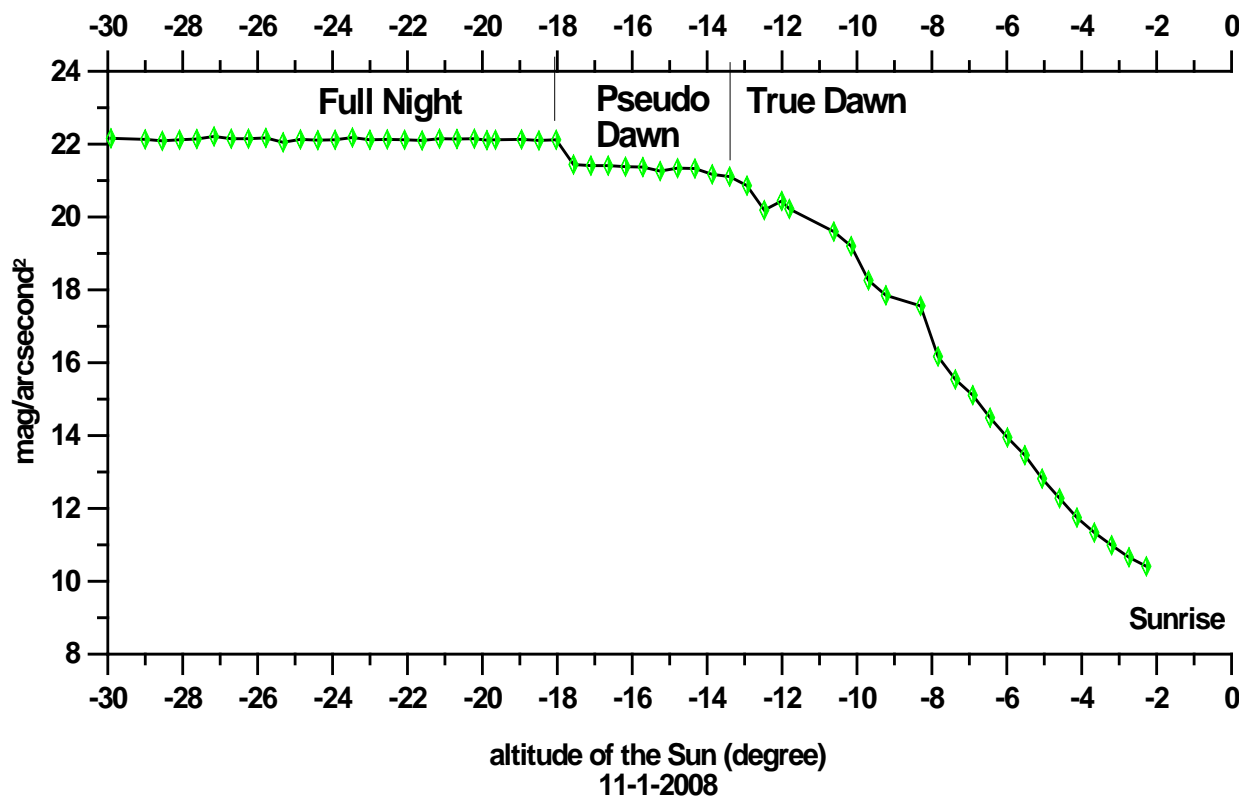

Figure 8. The relation between the light magnitude (mag./arcsec ${ }^{2}$ ) and altitude (a) of the sun for different time interval of the morning twilight for the full night, the pseudo-dawn (zodiacal light) and the true dawn on $11^{\text {th }}$ January 2008 in Kuala Lipis.

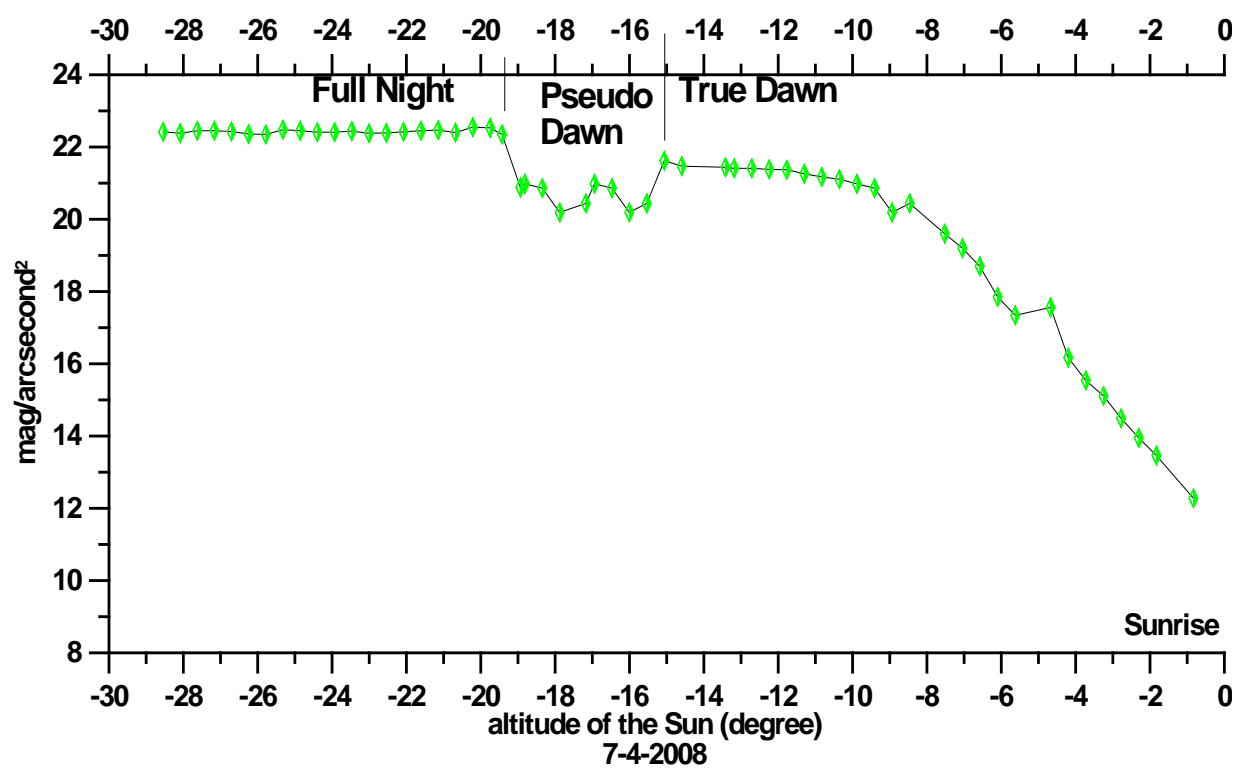

Figure 9. The relation between the light magnitude (mag./arcsec ${ }^{2}$ ) and altitude (a) of the sun for different time interval of the morning twilight for the full night, the pseudo dawn (zodiacal light) and the true dawn on $7^{\text {th }}$ April 2008 in Port Klang.

and the area of the pseudo dawn vary daily and are not constant. There is a range of about $0.6^{\mathrm{m}}$ in the amount of light magnitudes in some nights due to the difference in the atmosphere luminance between winter and summer, which is in turn due to the difference in temperature and humidity between each of them.

Figure 10 shows the relation between the light magnitude (mag./ $/ \mathrm{arsec}^{2}$ ) and altitude (a) of the sun for different stages of the morning twilight from full night 
-30-28-26-24-22-20-18-16-14-12-10 -8 -6 - -4 - -2 r 0

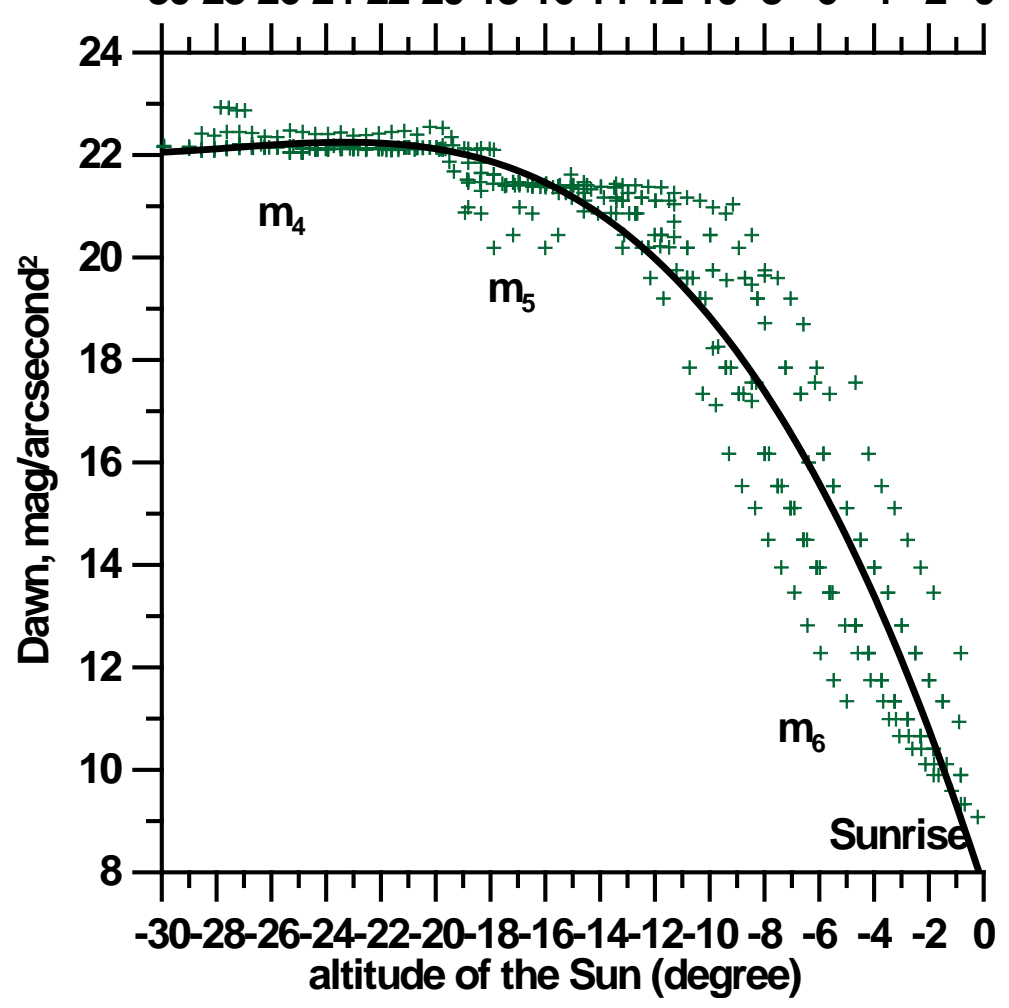

Figure 10. The relation between the light magnitude (mag./arcsec ${ }^{2}$ ) and altitude (a) of the sun for different time interval of the morning twilight for the full night, the pseudo-dawn (zodiacal light) and the true dawn for all days of observation.

to the sunrise for all observation days. It is very clear that the change in the total night light before the pseudo dawn is very slight around $22^{\mathrm{m}}$ and the full hierarchical shape of the pseudo dawn does not occur every day, while the rest cases of the pseudo dawn look as a transverse line that remains generally for four degrees between sun altitudes $-14.5^{\circ}$ and $-18.5^{\circ}$.

Table 7 represents the values of the light magnitude (mag./ $\operatorname{arcsec}^{2}$ ) and the depression of the sun (a) for all of the beginning and end of the true dawn $\left(m_{6}\right)$ and pseudo dawn $\left(m_{5}\right)$ for all of the observation days. From this table, the light magnitude of the beginning of the pseudo dawn is $21.48^{\mathrm{m}} \pm 0.282$, of the end of pseudo dawn is $21.21^{\mathrm{m}} \pm 0.33$ and of the beginning of the true dawn is $21.22^{\mathrm{m}} \pm$ 0.25 . The corresponding values of the altitudes of the sun (a) of these levels are: $-19.19^{\circ} \pm 0.78^{\circ},-14.76^{\circ} \pm 0.41^{\circ}$ and $-14.19^{\circ} \pm 0.52^{\circ}$ respectively. The high confidence for the true dawn which can be calculated from (mean $+\mathrm{SD}$ ) is $-14.71^{\circ}$.

Table 8 represents the full night altitude and magnitude limits $\left(\Delta a_{4}\right.$ and $\left.m_{4}\right)$ and pseudo dawn altitude and magnitude limits $\left(\Delta a_{5}\right.$ and $\left.m_{5}\right)$ as well, where $\Delta a_{i}$ represents the range of the altitude depression values and $m_{i}$ represents the light magnitude for the corresponding light regions. The difference in magnitude between the zodiacal light (pseudo dusk) and the full darkness is about one magnitude (from $20.77^{\mathrm{m}} \pm 0.87$ to $19.77^{\mathrm{m}} \pm 0.93$ ). The standard deviation (SD) of the observation days of the pseudo dawn $\left(m_{5}\right)$ ranges from $0.055^{\mathrm{m}}$ to $0.329^{\mathrm{m}}$ which 
Table 7. The beginning and end of the true and the pseudo dawn in terms of light magnitude $m_{i j}$ (mag./arcsec ${ }^{2}$ ) and sun vertical depression $\left(a_{i j}\right)$ below the horizon on the days of observation.

\begin{tabular}{ccccccc}
\hline Dawn & \multicolumn{2}{c}{ Beginning of pseudo dawn } & \multicolumn{2}{c}{ End of pseudo dawn } & \multicolumn{2}{c}{ Beginning of true dawn } \\
\hline Date & $m_{45}$ & $a_{45}$ & $m_{56}$ & $a_{56}$ & $m_{6}$ & $a_{6}$ \\
\hline $8-5-2007$ & 21.46 & -18.81 & 21.37 & -15.06 & 21.26 & -14.595 \\
$10-11-2007$ & 21.68 & -19.34 & 21.11 & -14.56 & 20.86 & -14.079 \\
$29-12-2007$ & 21.47 & -17.17 & 21.37 & -15.06 & 20.9 & -14.595 \\
$11-1-2008$ & 21.44 & -17.57 & 21.33 & -14.33 & 21.17 & -13.864 \\
$9-2-2008$ & 21.87 & -19.5 & 21.26 & -14.60 & 21.17 & -13.419 \\
$22-3-2008$ & 21.51 & -18.81 & 21.41 & -14.48 & 21.38 & -13.97 \\
$23-3-2008$ & 21.51 & -18.81 & 21.41 & -14.48 & 21.38 & -13.97 \\
$7-4-2008$ & 20.88 & -18.93 & 20.44 & -15.53 & 21.62 & -15.065 \\
Mean & 21.48 & -18.62 & 21.21 & -14.76 & 21.218 & -14.195 \\
SD & 0.282 & 0.82 & 0.33 & 0.412 & 0.2535 & 0.52145 \\
\hline
\end{tabular}

Table 8. The full night interval and pseudo dawn limit of light magnitude $m_{i}$ (mag./arcsec ${ }^{2}$ ) and the sun vertical depression (a) below the horizon on the days of observation.

\begin{tabular}{ccccc}
\hline Dawn & \multicolumn{2}{c}{ Full night } & \multicolumn{2}{c}{ Pseudo dawn limits } \\
\hline Date & $\Delta a_{4}$ & $m_{4}$ & $\Delta a_{5}$ & $m_{5}$ \\
\hline $8-5-2007$ & 10.17 & $22.133 \pm 0.033$ & 3.748 & $21.405 \pm 0.055$ \\
$10-11-2007$ & 6.85 & $22.133 \pm 0.033$ & 4.78 & $21.384 \pm 0.16$ \\
$29-12-2007$ & 10.66 & $22.133 \pm 0.033$ & 2.111 & $21.41 \pm 0.037$ \\
$11-1-2008$ & 11.89 & $22.13 \pm 0.031$ & 3.24 & $21.368 \pm 0.057$ \\
$9-2-2008$ & 9.71 & $22.133 \pm 0.033$ & 4.908 & $21.539 \pm 0.221$ \\
$22-3-2008$ & 10.17 & $22.14 \pm 0.035$ & 4.333 & $21.484 \pm 0.092$ \\
$23-3-2008$ & 9.63 & $22.14 \pm 0.035$ & 4.333 & $21.477 \pm 0.09$ \\
$7-4-2008$ & 9.11 & $22.43 \pm 0.053$ & 3.4 & $20.647 \pm 0.329$ \\
Mean & 9.77 & 22.17 & 3.856 & 21.34 \\
SD & 1.44 & 0.036 & 0.930 & 0.285 \\
Variance & & 0.001296 & & 0.0816 \\
\hline
\end{tabular}

expresses the greatest stability for each single night for that light interval, while the values of the full night were $\left(m_{4}\right)$ are from $0.031^{\mathrm{m}}$ to $0.053^{\mathrm{m}}$. This means that the stability in the full night is relatively higher in the case of pseudo dawn because of the increase of the radiation reflected from the light of the zodiacal light, especially from the asteroids belt between Mars and Jupiter (Reach 1997). The lowest stability in the pseudo dawn area appeared on $8^{\text {th }}$ May 2007 and April 7, 2008 because these two days had the hierarchical shape of the pseudo dawn as shown in Figure 9. The light magnitude values on $7^{\text {th }}$ April 2008 for the full night is $22.43^{\mathrm{m}} \pm 0.053$ as shown in Figure 9 and Table 8, which indicates the 
highest value of darkness during the observation period. Therefore, the condition of appearance of the hierarchical shape during the pseudo dawn appears in the very dark nights. The mean value of light magnitude at full night is larger than that of light magnitude of the pseudo dawn $\left(22.17^{\mathrm{m}} \pm 0.036>21.34^{\mathrm{m}} \pm\right.$ 0.285). The difference in the sun vertical depression between the beginning and the end of the pseudo dawn $\Delta a$ is about $4^{\circ}$, while the deference between the beginning of the pseudo and the true dawns is about $\approx 4.5^{\circ}$. The difference in light magnitude of the zodiacal light interval (pseudo dawn) is about $0.83^{\mathrm{m}}$ (from $22.17^{\mathrm{m}} \pm 0.036$ to $21.34^{\mathrm{m}} \pm 0.285$ ), which represents the difference between the mean values of the magnitudes of the full night and the pseudo dawn. Also, from Table 8 , it is noticed that the values of the variance for both the pseudo dawn $\left(m_{5}=0.0816^{\mathrm{m}}\right)$ and the full night $\left(m_{4}=0.0013^{\mathrm{m}}\right)$ are different from each other, which represents a remarkable change. This indicates that the stability in the darkness in the case of the full night is much higher than in the case of the pseudo dawn.

\subsection{Comparison between the Results of the Evening and the Morning Twilight}

Figure 11 and Table 5 show the different stages of the light magnitude from sunset to sunrise for the evening twilight of $22^{\text {nd }}$ March 2008 followed by the morning twilight of $23^{\text {rd }}$ March 2008. It is noticed that the pseudo dusk on $22^{\text {nd }}$ March 2008 is clearly discriminated from the rest of the days during the sun vertical depression range of $-14.5^{\circ}<a<-18.8^{\circ}$. Similarly, Figure 12 shows the different stages of light magnitude from sunset to sunrise at the evening twilight of $6^{\text {th }}$ April 2008 followed by the morning twilight of $7^{\text {th }}$ April 2008. Finally, Figure 13 shows the different stages of light magnitude from sunset to sunrise at the

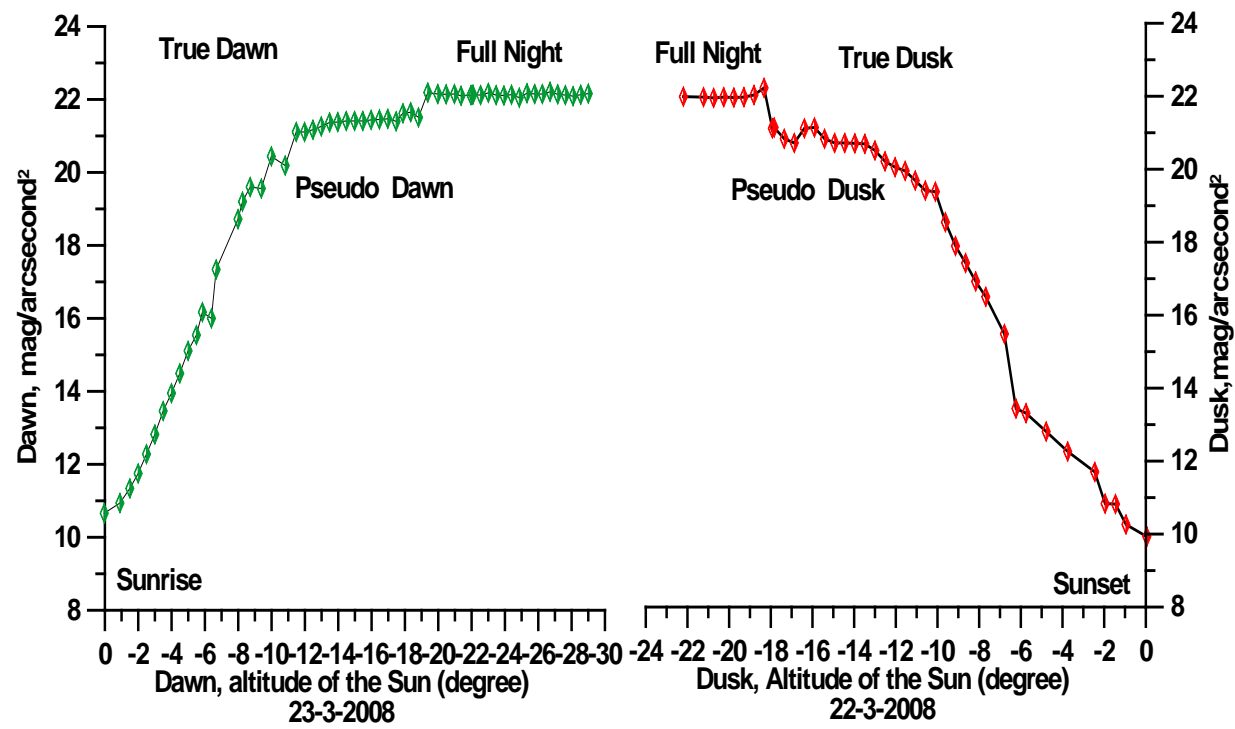

Figure 11. The relation between the light magnitude (mag./ $a r c s e c^{2}$ ) and altitude (a) of the sun for different time intervals from sunset to sunrise at the evening of $22^{\text {nd }}$ March 2018 followed by the morning of $23^{\text {rd }}$ March 2018. 


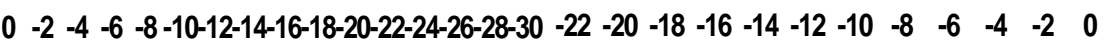
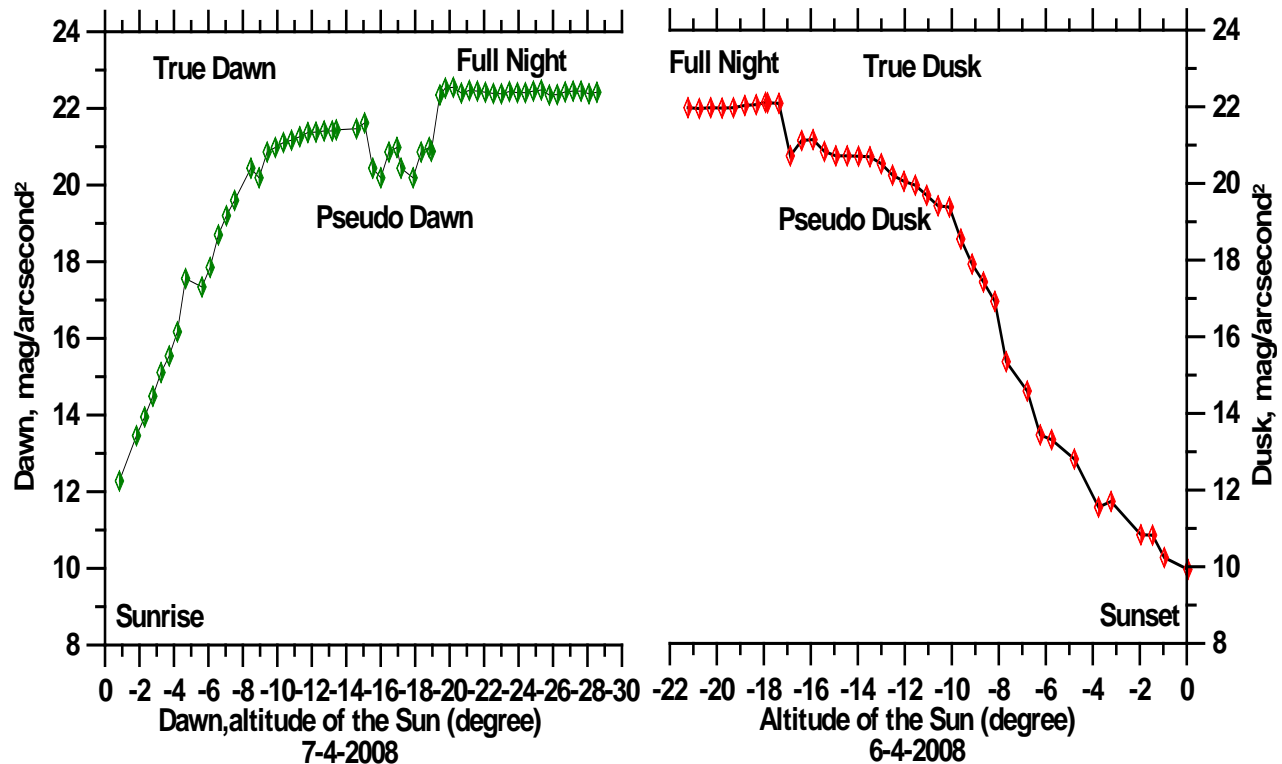

Figure 12. The relation between the light magnitude (mag./ $\operatorname{arcsec}^{2}$ ) and altitude (a) of the sun for different time intervals from sunset to sunrise at the evening of $6^{\text {th }}$ April 2018 followed by the morning of $7^{\text {th }}$ April 2018.

0 -2 -4 -6 -8 - -10-12-14-16-18-20-22-24-26-28-30-26-24-22-20-18-16-14-12-10 -8 -6 -6 -4 -2 0
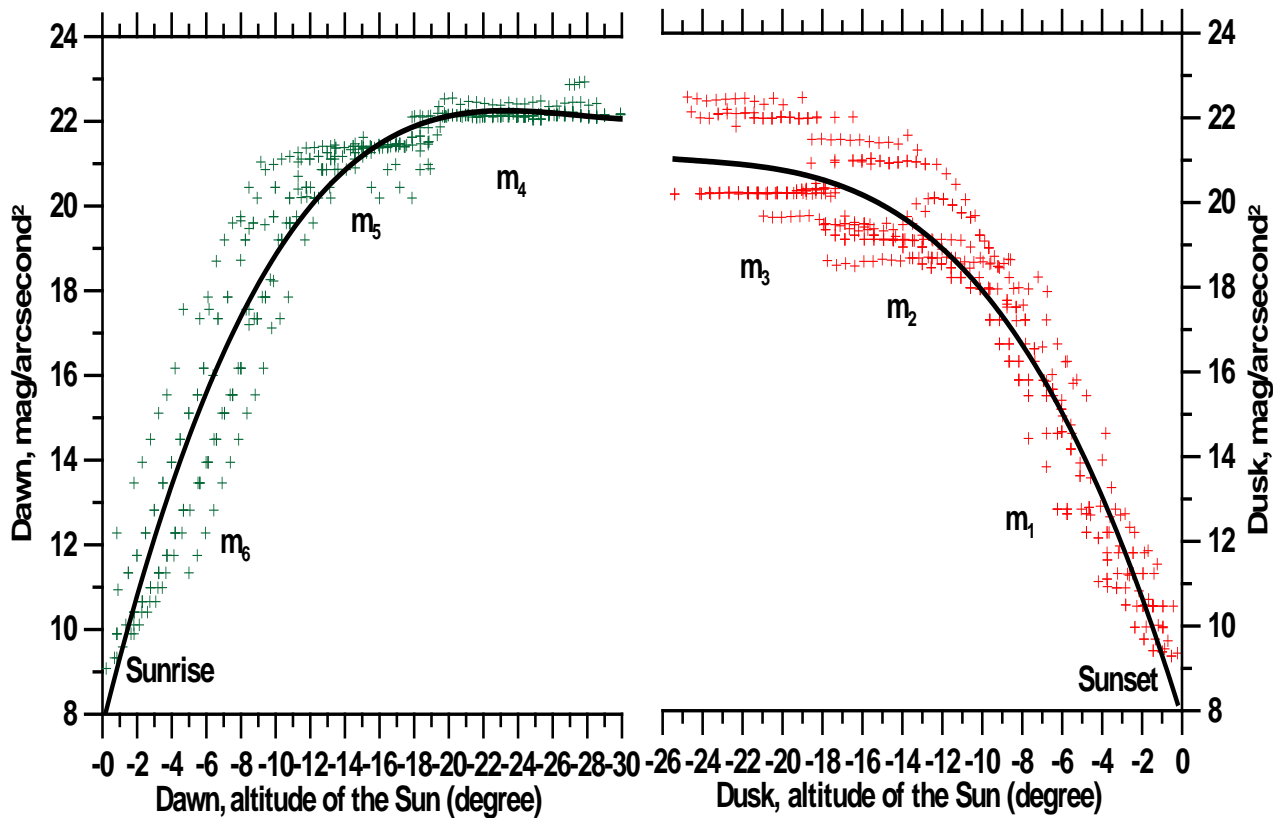

Figure 13. The relation between the light magnitude (mag./arcsec ${ }^{2}$ ) and altitude (a) of the sun for different time interval from sunset to sunrise at the evening followed by the morning of total days under the study.

evening twilight followed by the morning twilight of total days under the study. Generally, there is approximation of the different stages of light between the true dusk and the true dawn at the sun altitude rounding about $-14^{\circ}$, and between the end of the pseudo dusk and the beginning of the pseudo dawn a sun altitude 
rounding about $-18^{\circ}$. The full night before the pseudo-dawn is more stable than the full night after the pseudo-dusk.

\subsubsection{Comparison between the True Dusk and the True Dawn}

Figure 14 shows that the decrease rate of the light magnitude by altitude change $(\mathrm{dm} / \mathrm{da})_{1}$ for the true dusk is 0.827 (mag.arcsec ${ }^{-2} \cdot$ degree $\left.^{-1}\right)$, while that for the true dawn $(\mathrm{dm} / \mathrm{da})_{6}$ is $0.942\left(\mathrm{mag} \cdot \operatorname{arcsec}^{-2} \cdot \operatorname{degree}^{-1}\right)$. This means that the rate of increase of light magnitude at true dawn is greater than the light magnitude rate of decrease at true dusk by $12.2 \%$. This can be interpreted in terms of the high temperature in the dusk compared to the dawn and the consequent increase in the radiation energy of the atmosphere in the dusk compared to dawn at the same interval of altitude of the sun (between $0^{\circ}$ and $14^{\circ}$ ). The relation between the light magnitude $\left(m_{1}\right)$ of the true dusk and the altitude of the sun $\left(a_{1}\right)$, and light magnitude $\left(m_{6}\right)$ of the true dawn and altitude of the sun $\left(a_{6}\right)$ can be expressed in the following empirical relations:

For the dusk:

$$
m_{1}=9.3519-0.8271 a_{1}
$$

with a correlation coefficient $\mathrm{CC}=0.957$

For the dawn:

$$
m_{6}=9.3276-0.942 a_{6}
$$

with a correlation coefficient $\mathrm{CC}=0.941$

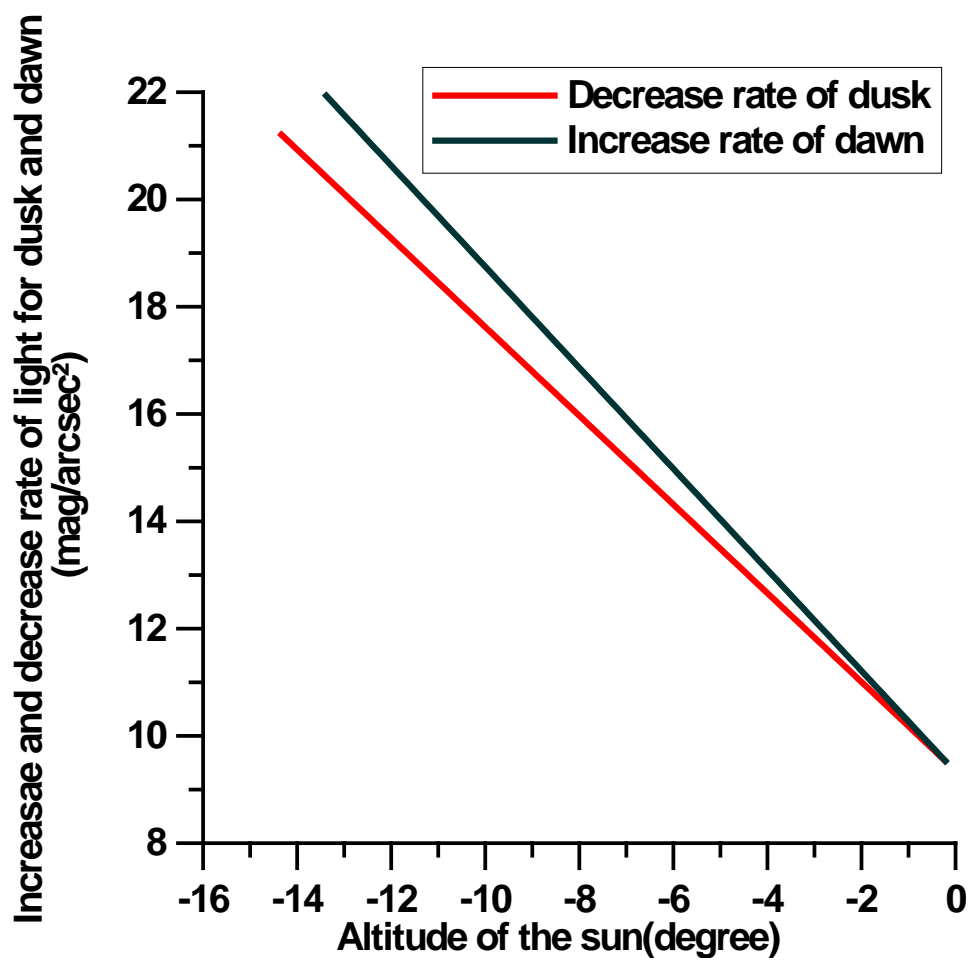

Figure 14. The rate of the decrease of the light magnitude by altitude change $(\mathrm{dm} / \mathrm{da})_{1}$ for the true dusk and the increase the light magnitude by altitude change $(\mathrm{dm} / \mathrm{da})_{6}$ for the true dawn respectively for the days of observation. 
Generally, the constants $9.35^{\mathrm{m}}$ and $9.32^{\mathrm{m}}$ represents the light magnitude at sunset and sunrise respectively, which indicates that there is a slight difference in the light magnitude between sunrise and sunset, which means that the selected areas for observation are typical.

\subsubsection{Comparison between the Pseudo Dusk and the Pseudo Dawn}

Table 5 and Table 7 showed the comparison between the end of the pseudo dusk and the beginning of the pseudo dawn in terms of the light magnitude values and the depression of the sun under the horizon. The beginning of the pseudo dusk occurs at light magnitude value $19.78^{\mathrm{m}} \pm 0.87$ and sun altitude $-14.86^{\circ} \pm$ $0.91^{\circ}$, while the end of the pseudo dawn occurs at light magnitude value $21.48^{\mathrm{m}}$ \pm 0.28 and sun altitude $-14.76^{\circ} \pm 0.41^{\circ}$. On the other hand, the end of the pseudo dusk occurs at light magnitude value is $20.06^{\mathrm{m}} \pm 0.927$ and sun altitude $-17.8^{\circ} \pm 0.697^{\circ}$, while the beginning of the pseudo dawn occurs at light magnitude value $21.21^{\mathrm{m}} \pm 0.25$ and sun altitude $-18.48^{\circ} \pm 0.28^{\circ}$. This means that the phenomenon of the twilight is reversible for both of its sides around the sun altitude value of $-18^{\circ}$ (astronomical twilight). The hierarchical shape is clearer in the case of the pseudo dawn than in the case of the pseudo dusk (see Figure 11 and Figure 12). This is due to the stability of the weather condition, which is higher in the case of the pseudo dawn than in the case of the pseudo dusk.

\subsubsection{Comparison between the Full Night after the Pseudo Dusk and Full Night before the Pseudo Dawn}

It is clear that from Table 6 and Table 8 of the total days that the full night before the morning twilight $\left(m_{4}=22.17^{\mathrm{m}} \pm 0.036\right)$ is more stable than that after the evening twilight $\left(m_{3}=20.77^{\mathrm{m}} \pm 0.93\right)$. This appears in the values of the standard deviation (SD), whose value of the dawn is less than that of the dusk $(0.036<$ 0.93). The difference of the light magnitude for the full night after the pseudo dusk $\left(\Delta m_{3}=2 \mathrm{SD}=1.86^{\mathrm{m}}\right)$ is greater than that before the pseudo dawn $\left(\Delta m_{4}=\right.$ $\left.2 \mathrm{SD}=0.072^{\mathrm{m}}\right)$. The difference in the light magnitude values between the full night and the pseudo dusk is $1^{\mathrm{m}}\left(19.77^{\mathrm{m}}-20.77^{\mathrm{m}}\right)$, while that between the full night and the pseudo dawn is $0.83^{\mathrm{m}}\left(22.17^{\mathrm{m}}-21.34^{\mathrm{m}}\right)$.

Table 9 and Figure 15 represent the final outcome of the morning and evening twilight against the altitude of the sun. By comparing our results with the results of previous researches shown in Table 1, we can see a high compatibility. The difference is one degree between the end of the pseudo dusk $\left(-17.66^{\circ} \pm\right.$ $\left.0.83^{\circ}\right)$ and the beginning of the pseudo dawn $\left(-18.62^{\circ} \pm 0.82^{\circ}\right)$. It is clearly noticed that the first light appearing in the dawn of Miethe and Lehmann (1909) in Aswan was at $17.35^{\circ}$, which is the beginning of the pseudo dawn. This agrees with our results $\left(-17.66^{\circ} \pm 0.83^{\circ}\right)$.

\subsubsection{Comparison between the Major Levels of the Twilight Magnitude at $-6^{\circ},-12^{\circ}$ and $-18^{\circ}$ of the Evening and the Morning Twilight}

Table 10 and Table 11 represent the major levels of the twilight magnitude (mag./arcsec ${ }^{2}$ ) of the dusk and the dawn for the sun altitudes $-6^{\circ},-12^{\circ}$ and $-18^{\circ}$ 
Table 9. The final outcome of the morning and evening twilight against the altitude of the sun.

\begin{tabular}{lcc}
\hline True dusk $\left(-14.38^{\circ} \pm 0.91^{\circ}\right)$ & $\begin{array}{c}\text { Beginning of the pseudo } \\
\text { dusk }\left(-14.86^{\circ} \pm 0.91^{\circ}\right)\end{array}$ & $\begin{array}{c}\text { End of the pseudo dusk } \\
\left(-17.8^{\circ} \pm 0.7^{\circ}\right)\end{array}$ \\
\hline True dawn $\left(-14.19^{\circ} \pm 0.52^{\circ}\right)$ & $\begin{array}{c}\text { End of the pseudo dawn } \\
\left(-14.76^{\circ} \pm 0.41^{\circ}\right)\end{array}$ & $\begin{array}{c}\text { Beginning of the pseudo } \\
\text { dawn }\left(-18.62^{\circ} \pm 0.82^{\circ}\right)\end{array}$ \\
\hline
\end{tabular}

Table 10. The major level of the evening twilight magnitude $m$ (mag./arcsec ${ }^{2}$ ) from sunset (at $\left.a=-0.76^{\circ} \pm 0.21^{\circ}\right)$ until the end of the twilight.

\begin{tabular}{ccccc}
\hline Dusk & Sunset & $-6^{\circ}$ & $-12^{\circ}$ & $-18^{\circ}$ \\
\hline Date & $m$ & $m$ & $m$ & $m$ \\
\hline $15-06-2007$ & 9.65 & 14.6 & 20.09 & 21.5 \\
$13-8-2007$ & 10.47 & 15.33 & 20.72 & 21.5 \\
$12-1-2008$ & 9.29 & 15 & 18.9 & 20.2 \\
$9-2-2008$ & 9.29 & 16.45 & 19.13 & 20.22 \\
$22-3-2008$ & 9.46 & 12.7 & 18.55 & 19.7 \\
$23-3-2008$ & 10.47 & 12.7 & 18.55 & 19.6 \\
$5-4-2008$ & 9.98 & 13.65 & 18.33 & 20.32 \\
$6-4-2008$ & 9.98 & 12.7 & 18.55 & 20.33 \\
$7-4-2008$ & 10.47 & 14.6 & 20.09 & 20.94 \\
Mean & 9.89 & 14.192 & 19.212 & 20.48 \\
SD & 0.498 & 1.34 & 0.867 & 0.695 \\
\hline
\end{tabular}

Table 11. The major levels of the morning twilight magnitude $m$ (mag./arcsec ${ }^{2}$ ) until sunrise (at $a=-0.83^{\circ} \pm 0.06^{\circ}$ ).

\begin{tabular}{ccccc}
\hline Dawn & Sunrise & $-6^{\circ}$ & $-12^{\circ}$ & $-18^{\circ}$ \\
\hline Date & $m$ & $m$ & $m$ & $m$ \\
\hline $8-5-2007$ & 9.90 & 13.90 & 20.20 & 21.40 \\
$10-11-2007$ & 9.33 & 12.40 & 19.50 & 21.43 \\
$29-12-2007$ & 9.90 & 13.90 & 20.30 & 22.10 \\
$11-1-2008$ & 9.33 & 13.97 & 20.44 & 22.10 \\
$9-2-2008$ & 9.90 & 13.90 & 20.30 & 21.75 \\
$22-3-2008$ & 9.90 & 16.70 & 21.11 & 21.63 \\
$23-3-2008$ & 10.94 & 16.06 & 21.11 & 21.63 \\
$7-4-2008$ & 10.94 & 17.60 & 21.36 & 20.50 \\
Mean & 10.02 & 14.80 & 20.54 & 21.567 \\
SD & 0.621 & 1.7694 & 0.614 & 0.506 \\
\hline
\end{tabular}




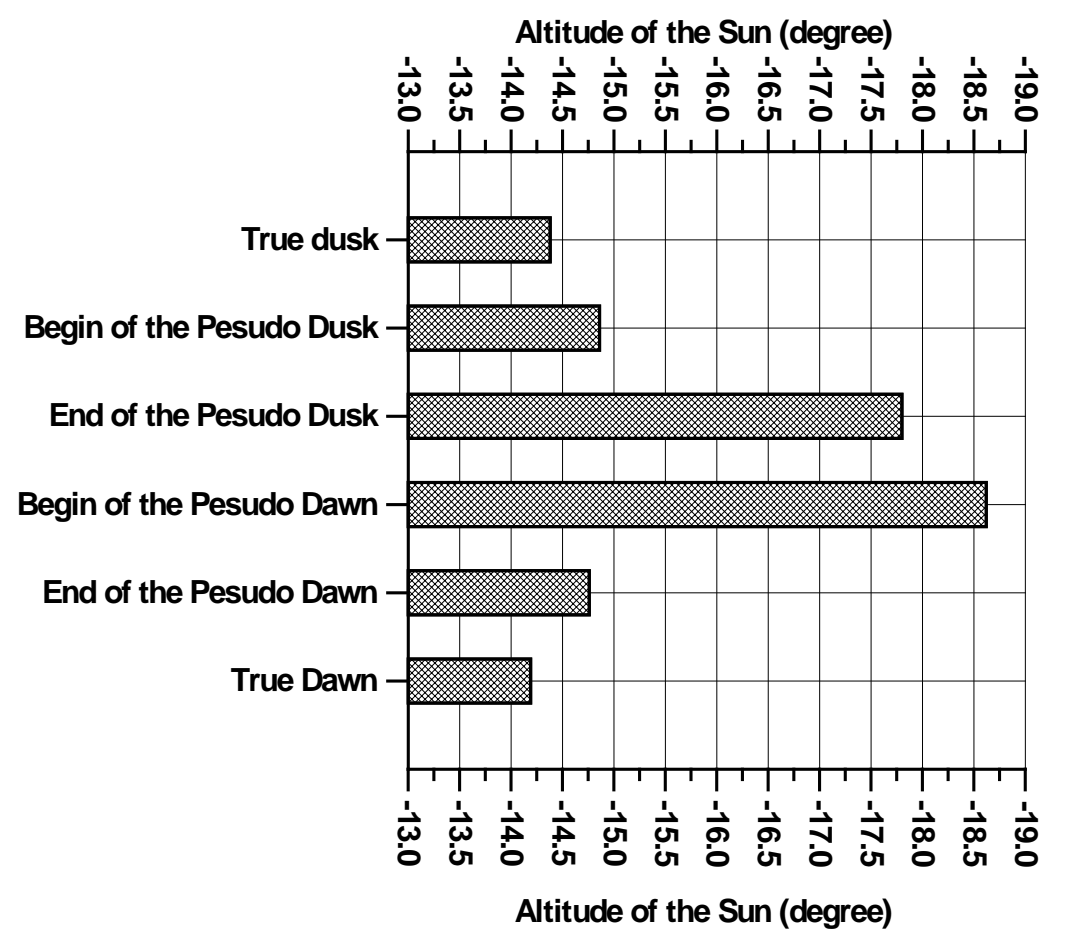

Figure 15. The mean values of the final outcome of the morning and the evening twilight sequences against the altitude of the sun.

representing the borders of the twilight types on the days of observation. We observed an increase in the light magnitude by the decrease of the sun altitude. Comparing the results of the major levels of twilight magnitude of the dusk between Table $10\left(14.19^{\mathrm{m}} \pm 1.34,19.12^{\mathrm{m}} \pm 0.86\right.$ and $\left.20.48^{\mathrm{m}} \pm 0.69\right)$ and Table 2 $\left(12.42^{\mathrm{m}}, 19.03^{\mathrm{m}}\right.$ and $\left.21.79^{\mathrm{m}}\right)$, we can see that the difference between our study and the reference [14] is slight and increases slightly by decreasing the sun vertical depression under the horizon. The end of the evening twilight at Tanjung Aru in Malaysia was at a magnitude value of $20.79^{\mathrm{m}} \pm 0.36$ when the sun is below the horizon by a depression of $a=-18^{\circ} \pm 0.16$ [14].

Also, it is noticed from our work that the SD decreases with the altitude of the sun during the twilight intervals for the dusk and the dawn. The difference between both of them is slight and rounds about $0.25^{\mathrm{m}}$ between the light magnitude $m$ (mag./ $/ \mathrm{arcsec}^{2}$ ) for the sunset (which is $9.89^{\mathrm{m}} \pm 0.498$ and with high confidence is $10.388^{\mathrm{m}}$ ) and the sunrise (which is $10.02^{\mathrm{m}} \pm 0.62$ and with high confidence is $\left.10.64^{\mathrm{m}}\right)$. The light magnitude values of the sunrise and the sunset from Equation (1) and Equation (2) are around $9.32^{\mathrm{m}}$ at zero altitude according to the center of the sun disc. On the other hand, the light magnitude values in Table 10 and Table 11, which are between $9.89^{\mathrm{m}}$ and $10.02^{\mathrm{m}}$, are for the true sunset and the true sunrise and around altitude of $-0.76^{\circ}$ and $-0.83^{\circ}$ (after the absence of the entire sun disc). The SD of the light magnitude for the evening twilight are decreases with the increase of the sun depression by the values $1.34^{\mathrm{m}}, 0.867^{\mathrm{m}}$ and $0.695^{\mathrm{m}}$ respectively, which means that the stability in the night increases with the increase of the depression of the sun, where the diffuse radiation gets les shown 
in Table 10. The SD values of magnitude for the morning twilight at the same depression are $1.77^{\mathrm{m}}, 0.614^{\mathrm{m}}$ and $0.506^{\mathrm{m}}$ as shown in Table 11 .

\section{Future Work and Remarks}

We have not yet been able through photometric observations to determine the time period, the corresponding magnitude (mag./ $/ \operatorname{arsec}^{2}$ ) and the vertical depression under the horizon between the end of the pseudo dawn and the beginning of the true dawn (which is within one degree). We just detected a darkness time interval as a function of difference in altitude of the sun of about one degree (between $15.5^{\circ}$ and $14.5^{\circ}$ ) between the end of the pseudo dawn and the beginning of the true dawn. This period was observed in the observations of Riyadh in Saudi Arabia [10] as well as the observations of Wadi Al Natroun in Egypt [21]. Therefore, we would like to encourage the researchers, observers and the interested people in this field to achieve this task. Also, there must be a time lack between the beginning of the true dusk and the beginning of the pseudo dusk as is the case of the dawn. The time interval between the pseudo and true dusk and dawn should not be less than half minute. We need more eye and photometric observation for the pseudo dusk in different clean desert areas. It is clear from all of the researches that the eye observations are more accurate than the available devices so far. We also need more photometric research to find out the appropriate weather conditions in which the hierarchical shape of pseudo dawn and pseudo dusk appear. So far, the eye observations show some phenomena by different devices. Thus, the ability of the eye to differentiate between the colors exceeds any other device, which agrees the results of [3] and [27].

\section{Conclusions and Remarks}

Based on the aspect that each light region in the twilight has its own characteristics that distinguish it from other light regions, we have got the following results:

1) The full night sky magnitude after the pseudo dusk is $20.77^{\mathrm{m}} \pm 0.93$ with a variance $0.865^{\mathrm{m}}$, while the full night sky magnitude for pre-pseudo dawn is $22.17^{\mathrm{m}} \pm 0.104$ with a value of variance $0.0108^{\mathrm{m}}$. The full night sky before the pseudo dawn is more stable than the full night after the pseudo dusk.

2) The pseudo dusk boundary values of the altitude of the sun are from $a=$ $-17.8^{\circ} \pm 0.7^{\circ}$ to $a=-14.86^{\circ} \pm 0.91^{\circ}$ with a variance of light magnitude of $0.758^{\mathrm{m}}$. The pseudo dawn boundary values of the altitude of the sun are from $a=-18.62^{\circ} \pm 0.82^{\circ}$ to $a=-14.76^{\circ} \pm 0.41^{\circ}$ with a variance of the light magnitude of $0.0816^{\mathrm{m}}$.

3) Generally, the astronomical twilight $\left(18^{\circ}\right)$ is considered as the end of the pseudo dusk and the beginning of the pseudo dawn.

4) The beginning of the true dusk is at $19.63^{\mathrm{m}} \pm 0.92$ and $a=-14.38^{\circ} \pm 0.91^{\circ}$ (the high confidence value is $15.29^{\circ}$ ), while the beginning of the true dawn is at $21.22^{\mathrm{m}} \pm 0.25$ and $a=-14.19^{\circ} \pm 0.52^{\circ}$ (the high confidence value is $-14.71^{\circ}$ ). 
5) The major levels of the light magnitude for the civil, the nautical and the astronomical evening twilight are at $14.19^{\mathrm{m}} \pm 1.34,19.12^{\mathrm{m}} \pm 0.86$, and $20.48^{\mathrm{m}} \pm$ 0.69 respectively, while the major levels of the light magnitude for the civil, the nautical and the astronomical twilight for the morning twilight are at $14.80^{\mathrm{m}} \pm$ $1.77,20.54^{\mathrm{m}} \pm 0.61$, and $21.56^{\mathrm{m}} \pm 0.50$ respectively.

6) The light magnitude values are higher for the dawn than for the dusk at the major twilight types (civil, nautical and astronomical) by $0.5^{\mathrm{m}}, 0.75^{\mathrm{m}}$ and $1^{\mathrm{m}}$ respectively. The increase rate of the light magnitude for the true dawn is higher than the light magnitude decrease rate for the true dusk by $12.2 \%$ for the same altitude interval.

7) There is a similarity between the morning and the evening light regions of the pseudo dawn, the pseudo dusk, the true dawn and the true dusk. The symmetry is complete in case of air temperature equality between the dusk and the dawn.

8) The full hierarchical shape of the pseudo dusk or the pseudo dawn does not occur regularly. The difference in the light magnitude of the zodiacal light for the pseudo dusk is about $1^{\mathrm{m}}$ and for the pseudo dawn is $0.83^{\mathrm{m}}$.

The results of this work agree with that resulted by Miethe and Lehmann [4], Patat et al. [8] and our previously published work (Table 1), which assure the precision of the aspects, the observations and the analyses carried out in those articles.

\section{Acknowledgements}

The authors of this paper acknowledge Dr. Nur Nafhatun of the Academy of Contemporary Islamic Studies (ACIS), Universiti Teknologi MARA, Shah Alam, Selangor, Malaysia for providing us with the observation data recorded there by her team. Also, they thank Prof. Adalbert Ding professor of experimental Physics in the Institute of Optics and Atomic Physics of the Technical University of Berlin for his kind assistance in supporting the article by the paper titled "Dämmerungsbeobachtungen in Assuan in Winter 1908", authored by Miethe, A. and Lehmann, E., and published in Meteorologische Zeitschrift [4].

\section{Conflicts of Interest}

The authors declare no conflicts of interest regarding the publication of this paper.

\section{References}

[1] Tousey, R. and Koomen, M.J. (1952) Visibility of Stars and Planets during Twilight. Journal of Optical Society of America, 45, 177-183. https://doi.org/10.1364/JOSA.43.000177

[2] Rosenberg, G.V. (1966) Artplenum Press, New York.

[3] Beretta, G. (2008) Understanding Color. Hewlett-Packard Laboratories, Alexandria.

[4] Miethe, A. and Lehmann, E. (1909) Dämmerungsbeobachtungen in Assuan in win- 
ter 1908. Meteorologische Zeitschrift, 97-114.

[5] Nawar, S. (1978) Wide Band Spectral Photometry of the Zodiacal Light. Ph.D. Thesis, Faculty of Science, Cairo University, Cairo.

[6] Nesvorny, D., Jenniskens, P., Levison, H.F., Bottke, W.F., Vokrouhlicky, D. and Gounelle, M. (2010) Cometary Origin of the Zodiacal Cloud and Carbonaceous Micrometeorites, Implications for Hot Debris Disks. Astrophysical Journal, 713, 816-836. https://doi.org/10.1088/0004-637X/713/2/816

[7] Reach, W.T. (1997) The Structured Zodiacal Light: IRAS, COBE, and ISO Observations. Diffuse Infrared Radiation and the IRTS, ASP Conference Series Vol. 124.

[8] Patat, F., Ugolnikov, O.S. and Postylyakov, O.V. (2006) UBVRI Twilight Sky Brightness at ESO-Paranal. Astronomy and Astrophysics, 455, 385-393. https://doi.org/10.1051/0004-6361:20064992

[9] Kenyon, S.L. and Storey, J.W.V. (2006) A Review of Optical Sky Brightness and Extinction at Dome C, Antarctica. Publications of the Astronomical Society of the Pacific, 118, 489-502. https://doi.org/10.1086/499631

[10] Al Mostafa, Z.A., Kurdi, A.S., Al Marmash, A.S., Kurdi, M.N., Akhathlan, S.T., Al Kharge, M.S., Al Ganaam, A.G. and Al Saleh, S.O. (2005) Studying of Twilight Project. First Part, Abdul-Aziz City of the Science and Technology. Institute of Research Astronomy and Geophysics, Saudi Arabia.

[11] Issa, I.A. and Hassan, A.H. (2008) Evening and Morning Twilights at Bahria/Egypt. II. NRIAG Journal of Astronomy and Geophysics, Special Issue, 399-411.

[12] Issa, I.A. and Hassan, A.H. (2008) Eye Criteria and Times of End and Begin of Twilights. Bahria/Egypt. III. NRIAG Journal of Astronomy and Geophysics, Special Issue, 413-423.

[13] Issa, I.A., Hassanin, N.Y., Hassan, A.H. and Abdel-Hadi, Y.A. (2011) Atmospheric Transparency, Twilight Brightness and Color Indices at Kottamia of Egypt. NRIAG Journal of Astronomy and Geophysics, Special Issue, 379-398.

[14] Niri, M.A., Zainuddin, M.Z., Man, S., Nawawi, M.S.A.M., Wahab, R.A., Ismail, K., Zaki, N.H.A., Ghani, A.A. and Lokman, M.A.A. (2012) Astronomical Determinations for the Beginning Prayer Time of Isha. Middle-East Journal of Scientific Research (MESJR), 12, 101-107.

[15] Hassan, A.H., Hassanin, N.Y., Abdel-Hadi, Y.A. and Issa, I.A. (2013) Time Verification of Twilight Begin and End at Matrouh of Egypt. NRIAG Journal of Astronomy and Geophysics, 2, 45-53. https://doi.org/10.1016/j.nrjag.2013.06.008

[16] Hassan, A.H., Hassanin, N.Y., Abdel-Hadi, Y.A. and Issa, I.A. (2014) Brightness and Color Variation for Evening and Morning Twilight at Bahria of Egypt IV. NRIAG Journal of Astronomy and Geophysics, 3, 37-45. https://doi.org/10.1016/j.nrjag.2014.02.004

[17] Hassan, A.H., Hassanin, N.Y., Abdel-Hadi, Y.A. and Issa, I.A. (2014) Naked Eye Observations for Morning Twilight at Different Sites in Egypt. NRIAG Journal of Astronomy and Geophysics, 3, 23-26. https://doi.org/10.1016/j.nrjag.2014.02.002

[18] Hassan, A.H. and Abdel-Hadi, Y.A. (2015) Naked Eye Determinations of the Dawn at Tubruq of Libya through Four Years Observations. Middle East Journal of Scientific Research MEJSR, 23, 2627-2632.

[19] Hassan, A.H., Issa, I.A., Mousa, M. and Abdel-Hadi, Y.A. (2016) Naked Eye Determination of the Dawn for Sinai and Assiut of Egypt. NRIAG Journal of Astronomy and Geophysics, 5, 9-15. https://doi.org/10.1016/j.nrjag.2016.02.001

[20] Khalifa, N.S., Hassan, A.H. and Taha, A.I. (2018) Twilight Observation by the Naked 
Eye of the Dawn Sincere at Hail and Other Areas in Saudi Arabia. NRIAG Journal of Astronomy and Geophysics, 7, 22-26. https://doi.org/10.1016/j.nrjag.2018.01.001

[21] Semeida, M.A. and Hassan, A.H. (2018) Pseudo Dawn and True Dawn Observations by Naked Eye in Egypt. Beni-Suef University, Journal of Basic and Applied Sciences BJBAS, 7, 286-290. https://doi.org/10.1016/j.bjbas.2018.03.005

[22] Saksono, T. and Ali Fulazzaky, M. (2020) Predicting the Accurate Period of True Dawn Using a Third-Degree Polynomial Model. NRIAG Journal of Astronomy and Geophysics, Egypt, 9, 238-244. https://doi.org/10.1080/20909977.2020.1738106

[23] Sanchez de Miguel, A., Aube, M., Zamorano, J., Kocifaj, M., Roby, J. and Tapia, C. (2017) Sky Quality Meter Measurements in a Colour-Changing World. MNRAS, 467, 2966-2979. https://doi.org/10.1093/mnras/stx145

[24] Hänel, A., Posch, T., Ribas, S.J., Aubée, M., Duriscoe, D., Jechow, A., et al. (2018) Measuring Night Sky Brightness: Methods and Challenges. Journal of Quantitative Spectroscopy \& Radiative Transfer, 205, 278-290. https://doi.org/10.1016/j.jqsrt.2017.09.008

[25] Gokhale, V., Goins, J., Herdmann, A., Hilker, E. and Wren, E. (2019) Sky Brightness Measurements and Ways to Mitigate Light Pollution in Kirksville, Missouri. JAAVSO, 47, 241-247.

[26] Shariff, N.N.M. (2008) Sky Brightness at Twilight: Detectors Comparison between Human Eye and Electronic Device for Ishā’ \& Subḥ from Islamic and Astronomical Considerations. M.Sc. Thesis, Faculty of Science, Universiti Malaya, Kuala Lumpur.

[27] Valberg, A. (2005) Light Vision Color. John Wiley \& Sons Ltd., Hoboken. 